\title{
Calcium looping as chemical energy storage in concentrated solar power plants: Carbonator modelling and configuration assessment
}

\author{
Manuel Bailera $^{a *}$, Pilar Lisbona ${ }^{\mathrm{b}}$, Luis M. Romeo ${ }^{\mathrm{a}}$, Luis I. Díez ${ }^{\mathrm{a}}$ \\ a Escuela de Ingeniería y Arquitectura. Universidad de Zaragoza, Campus Río Ebro, María de Luna 3, \\ 50018, Zaragoza, Spain \\ ${ }^{\mathrm{b}}$ Fundación Agencia Aragonesa para la Investigación y el Desarrollo (ARAID), Zaragoza, Spain
}

\begin{abstract}
This paper addresses the analysis of different configurations of carbonator for thermochemical energy storage for concentrated solar applications. The design of this equipment is different from the previous experience of calcium looping cycle for carbon capture. The use of fluidized beds and large particles are not feasible for this novel application of calcium looping. New reactors and different arrangements for the carbonation process are necessary. The design of a carbonator reactor for a specific Calcium Looping-Concentrated Solar Power application has not been addressed yet in detail in literature. In this work, a comparison of single stage reactor, two parallel reactors and two reactors in series with intercooling are simulated to calculate conversion rates, gas temperatures and flow rates, and heat transfer rates to the external cooling fluid. The modelling encompasses fluid dynamics, lime conversion kinetics and heat transfer, which are solved using a 1-D discrete mesh. The third arrangement results in the most reasonable sizes, and larger conversion rates, avoiding the occurrence of internal reactor zones in which the reaction is inhibited. Energy balance components are also quantified for each configuration.
\end{abstract}

\section{Keywords}

Calcium-looping; Thermochemical energy storage; Concentrated solar power; Carbonation

\section{Introduction}

Nowadays, global warming is unequivocal and extensively endorsed by scientific community. In 2019, the global land-ocean surface temperature had increased $1.18{ }^{\circ} \mathrm{C}$ with respect to the period 1951-1980 [1][2]. Heat waves occur more often and last longer, while extreme precipitations have become more intense and frequent [3]. According to the IPCC (Intergovernmental Panel on Climate Change), this has affected many 
species that have shifted their geographic ranges, seasonal activities or migration patterns in response to ongoing climate changes. Moreover, hydrological systems are continuously altered, what harms fresh water resources and food production [3].

Carbon dioxide is the largest single contributor to these perturbations on the energy balance of the Earth, and human beings are undoubtedly the main source [3]. Current atmospheric $\mathrm{CO}_{2}$ concentration is increasing at the fastest ever observed rate (2.0 ppm/yr), peaking the average for May 2019 at $414.8 \mathrm{ppm}$ [4]. At the United Nations Climate Change Conference held in Paris at the end of 2015, about 190 countries agreed to reduce emissions of greenhouse gases (GHG). The aim is to limit global temperature increase below $2{ }^{\circ} \mathrm{C}$ by the year 2100, related to pre-industrial levels [5]. However, those scenarios that limit warming to $2{ }^{\circ} \mathrm{C}$ would require $\mathrm{CO}_{2}$ atmospheric concentrations below $450 \mathrm{ppm}$, which will be hardly accomplishable [3].

Key measures to achieve such mitigation lie in decarbonizing electricity and heat generation sector, since it produces more than two-fifths of global $\mathrm{CO}_{2}$ emissions [6]. The European Union Renewable Energy Directive sets a binding target of $20 \%$ final energy consumption from renewable sources by 2020 [7]. The role of renewable energy sources will be crucial for the reduction of European pollutant emissions while increasing the energy security through the massive penetration of local renewable energy sources (RES) and the diversification of energy vectors. The "EU Reference Scenario 2016" estimates that the share of electricity from renewable energy sources is expected to grow up to $37.2 \%$ by 2020 , to $43 \%$ by 2030 , and to $53 \%$ by 2050 [8].

RES present a number of barriers that limit their massive deployment. One of the most significant barriers is the control and management of fluctuations given the intermittent nature of the weather-dependent power generation systems. The security and stability of the electric grid would be strongly compromised if mismatches between supply and electrical demand could occur. This issue represents a significant limitation for the technical and economic feasibility of RES.

To achieve the ambitious European targets for RES deployment and to develop of an energy system based on a more diversified technology mix, which allows a perfect control and match of the energy production and the instantaneous demand, the proposal and development of innovative energy storage solutions is needed. In 
the short-term, the deployment of efficient and competitive technologies for energy storage represents one of the most challenging requirements for the energy system. Renewable energy production and energy storage capacity must grow in parallel in order to soften the intrinsic variability of RES production through storage. The different technical characteristics of the available methods for storing energy (e.g., discharge time, storage period, prices or materials) define how they are coupled with RES.

Concentrated solar power plants (CSP) can operate beyond sunlight hours only when they include energy storage. Thermal energy storage systems which operate at medium $\left(100{ }^{\circ} \mathrm{C}\right.$ to $\left.250{ }^{\circ} \mathrm{C}\right)$ to high temperature level (above $250{ }^{\circ} \mathrm{C}$ ) are preferred in CSP to achieve higher round-trip efficiencies [9]. The currently most mature are the molten salt systems [10] which are used in commercial installations. Nevertheless, alternative storage materials are under studies such as natural rocks and recycled ceramics made from industrial wastes [11]. Thermochemical energy storage (TCES) was proposed as an innovative possibility to face the variability of CSP production [12][13][14]. TCES is based in the transformation and storage of thermal solar energy into chemical bounds created through endothermic chemical reactions. The density of storage of TCES is larger than other alternatives and it represents a significant advantage. The reverse exothermic reaction will be used to release the stored thermal energy when it is demanded. Prieto et al. compared different TCES under investigation such as those based in three redox reactions, sulfur-based cycles, metal oxide reductionoxidation cycles, and perovskite-type hydrogen production, and metal oxide non-redox cycles [12]. They concluded that all these cycles are promising but the calcium carbonate is the one with most experimentation and potential economic feasibility. Thus, the use of $\mathrm{CaCO}_{3}$ in the Ca-looping process is an interesting TCES alternative given the wide experience in the carbonation/calcination equilibrium reaction, the wide availability of limestone and its low price [15].

The Ca-Looping ( $\mathrm{CaL}$ ) process has been extensively applied as a competitive option for $\mathrm{CO}_{2}$ capture [16][17][18] but also proposed as TCES in CSP plants [12][15][19]. As stated, CaL process is based upon the reversible carbonation/calcination reaction in which limestone and lime are alternatively converted. Surplus solar energy can be chemically stored through the direct endothermic calcination of limestone at high temperatures 
producing pure streams of $\mathrm{CaO}$ and $\mathrm{CO}_{2}$. The stored energy will be released by means of the reverse reaction, exothermic carbonation reaction, at relatively high temperatures suitable for power cycles, both Brayton and Rankine cycles, when electricity demand raises. Chacartegui et al. and Ortiz et al. have demonstrated an outstanding performance under both situations; i.e. for a regenerative Rankine cycle an efficiency of $35.5 \%$ has been presented, but it increases to near $39.0 \%$ for a combined cycle or $42.0 \%$ for a closed Brayton cycle [15][19]. As highlighted by Bayon et al., $\mathrm{CaL}$ is also suitable for supercritical $\mathrm{CO}_{2}$ cycles [20].

The Ca-L process applied as TCES starts with the decomposition of $\mathrm{CaCO}_{3}$ in the solar calcination reactor producing $\mathrm{CaO}$ and $\mathrm{CO}_{2}$. Apart from the heat requirements in the calcination reaction, high-energy input is needed to increase the temperature of inlet streams up to the required value for the calcination reaction to occur at a sufficiently fast rate. This temperature is essentially determined by the $\mathrm{CO}_{2}$ equilibrium [21]. Once the sensible heat of outlet streams is recovered, the $\mathrm{CaO}$ and $\mathrm{CO}_{2}$ produced are stored at ambient temperature for their subsequent use. Storage of the products could be extended from weeks to months depending on storage conditions and energy demand pattern [22]. The reactants will be recirculated into a carbonator reactor where chemical energy is released through the exothermic carbonation reaction when energy is demanded.

Detailed reviews of this TCES concept have been previously published [12][23][24][25][26] and there is a general agreement on the potential economic feasibility of carbonate systems as future TCES system if their cyclic stability and reversibility are improved. A key variable on the system is the activity of the sorbent. Cyclic limestone calcination leads to a strong deactivation of $\mathrm{CaO}$ under specific conditions for $\mathrm{CaL} \mathrm{CO}_{2}$ capture which imply high calcination temperatures under high $\mathrm{CO}_{2}$ partial pressure [18] and this decay of $\mathrm{CaO}$ sorbent capacity is assumed to also limit the efficiency of the CaL process for TCES [27]. Recent thermogravimetric analysis studies confirm that calcination/carbonation conditions that optimize the efficiency of the CSP-CaL integration are different than those that optimize $\mathrm{CO}_{2}$ capture applications [28]. The lower calcination temperature in CSP-CaL applications, the more limited sintering in the $\mathrm{CaO}$ and the higher efficiency of the $\mathrm{CaL}$ process. A better heat distribution in the calciner keeps the temperature profile along the reactor in the proper 
range, thus leading to less sintering of lime particles, faster reactions and minimum energy consumption in this element.

Improvements in sorbent activity levels do not affect efficiency but capital costs and reductions in the required storage volume [29]. One of the most significant advantages of the CSP-CaL integration is the use of natural limestone as $\mathrm{CaO}$ precursor. Limestone is an abundant, non-toxic and cheap material $(6-10 € / \mathrm{t})$, which presents suitable physical properties in the temperature range of interest for CSP thermal energy storage. In spite of that, different groups of researchers looks for sorbent improvements analysing the multicycle activity of the natural $\mathrm{CaCO}_{3}$ minerals [30]; doping and modifying $\mathrm{CaCO}_{3}[31][32]$, pre-processing limestone to enlarge the long-term performance of the sorbent upon iterated cycles [33], and developing synthetic Ca-based materials for energy storage [34].

Further challenges of the CaL technology are the low thermal conductivity of the sorbents, its agglomeration disposition causing the carbonation reaction to slow down and the difficulty in the design of the reactors for their efficient integration [23]. Chen et al. also mentioned the last two challenges as main factors that determine the heat storage performance, having reactors design an important role in the establishment of a reliable energy charging and releasing energy process [24]. Thus, proper design of the main reactors, carbonator and calciner, must be proposed to achieve favorable efficiency values. The designs will be circumscribed to the process and reactor limitations that will influence on the performance of the overall system.

Recently, Zsembinszki et al. reviewed the reactor designs with potential use in thermochemical energy storage in concentrated solar power plants [35]. Their classification criteria of the reactors was the limiting step, which is essential for a proper design process, kinetics or diffusion controlled. Generally, thermal decomposition occurred in the calciner is controlled by chemical reaction, while solid-gas reaction in the carbonator is limited by internal and external diffusion of gas in the particle. The classification according the reactor type is divided in stack, fluidized and entrained beds. Fixed beds are recommended for solar catalytic reactions while fluidized beds and entrained beds are better suggested for reactions requiring good thermal transfer properties. 
Fluidized and entrained beds minimize the risk of hotspots and thermal instability and present higher heat transfer coefficients. In this review, only two designs for carbonation reactor for CaL-CSP are gathered among existing experimental rigs: (i) Ortiz et al. designed a pressurized fluidized bed [19] and (ii) a carbonator/calciner fluidized bed built and run by Nikulshina et al. [36].

The carbonation reactor is a key element of the process and represents a complex system where heterogeneous exothermic chemical reactions take place together with heat transport phenomena for the production of steam for the Rankine cycle. Thus, fluidized or entrained bed are preferred for the design of this equipment. Recent investigations of Ortiz et al. of the kinetics and process integration of CaL-CSP showed that TCES applications require much lower limestone particle size than the well-known CaL processes for carbon capture (80-300 microns) [37]. Limestone particle sizes of tens of microns are required for an adequate solar calcination [37]. This technical limitation has important implications in the design of both reactors, which could require entrained flow reactors when particles are classified as Geldart C.

Although several works proposed in literature show the theoretical models and simulation results of a carbonator reactor for carbon capture applications [38][39][40], up to now, the design of a carbonator reactor for a specific CaL-CSP application has not been addressed in detail. The main novelty of this study is the assessment of the conceptual design of a CaL-CSP carbonator and the influence of different parameters. In this work, the modelling of a future commercial-scale carbonator is described, in the frame of a new concentrated solar-based plant. Different lengths, diameters and configurations (one reactor, several reactors in parallel or in series) for a commercial carbonator are analysed, as well as the corresponding heat released. The diameter of the particles influences the reactor sizing through the residence times, and the heat transfer through the emissivity of the cloud of gas and particles.

\section{Carbonator design and studied configurations}

Based on the provided information, the modelled carbonator presents an internal co-current entrained flow design and it is covered with four sections of helical coiled heat exchangers $\left(\mathrm{cf}_{1}, \mathrm{cf}_{2}, \mathrm{cf}_{3}\right.$ and $\left.\mathrm{cf}_{4}\right)$ in which pressurized water enters at 300 bar and $350{ }^{\circ} \mathrm{C}$. The outlet conditions of each of the cooling fluid streams ( $\mathrm{cf}_{\text {out }}$ ) 
are set to achieve $600{ }^{\circ} \mathrm{C}$ and a maximum pressure loss of $20 \mathrm{bar}$, to allow integration with supercritical steam cycles [41] (see Figure 1 and Figure 2). Thus, the simulations will provide as results the required cooling fluid mass flows. Heat exchanger sections 1 and 2 present a counter-current flow, while section 3 and 4 a co-current flow with respect to the internal carbonator flow direction. Entrained flow configuration with external cooling is chosen to keep technical complexity low, which in turn would help reducing costs. Other cooling options more complex are out of the scope of this paper (e.g., internal helical coils with variable surface area along the axis of the reactor).

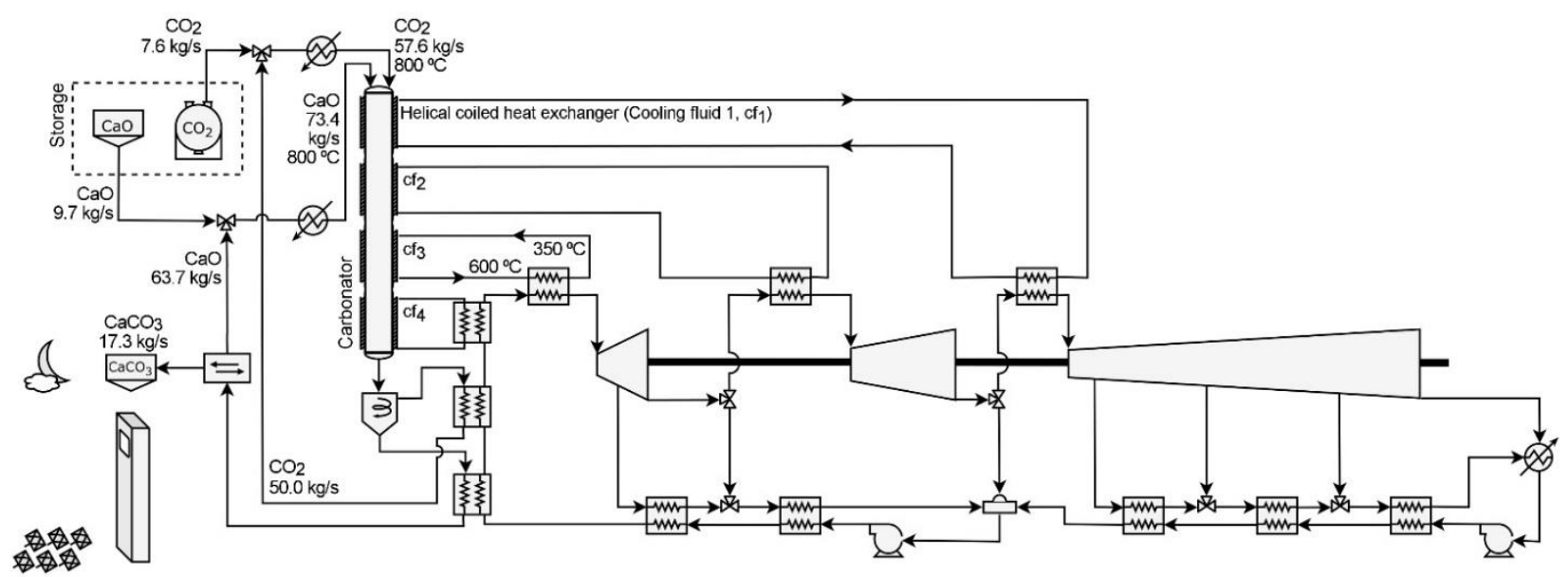

Figure 1. Conceptual design of the power production using a carbonator in a solar power plant (cf stands for cooling fluid).

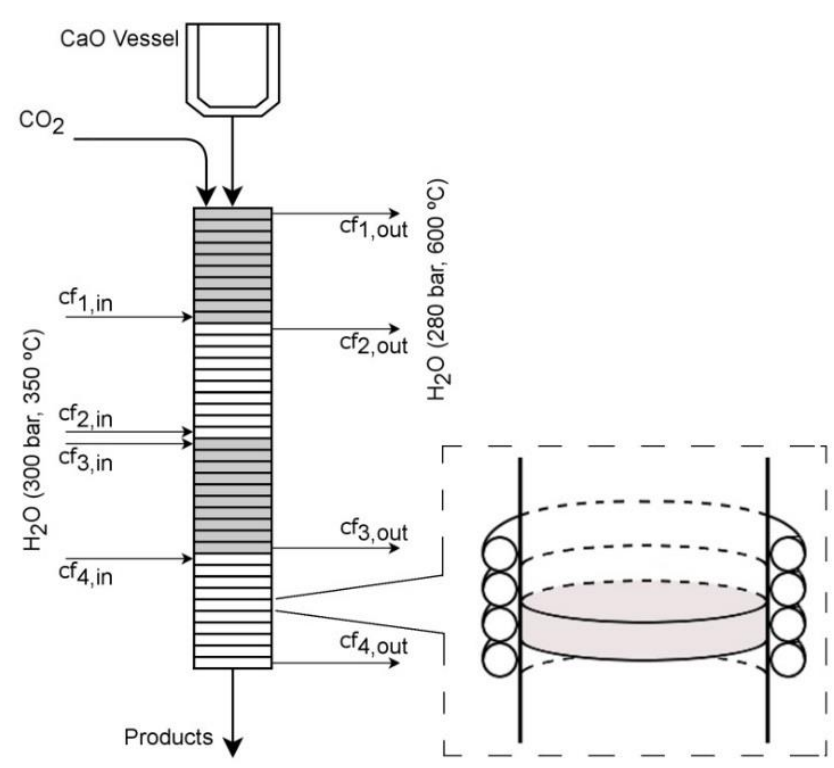

Figure 2. Conceptual design of the modelled carbonator (cf stands for cooling fluid). 
Total $\mathrm{CaO}$ and $\mathrm{CO}_{2}$ inlet mass flow rates are $73.41 \mathrm{~kg} / \mathrm{s}$ and $57.62 \mathrm{~kg} / \mathrm{s}$, respectively, and are assumed to enter to the carbonator at $800^{\circ} \mathrm{C}$. These mass flows correspond to the outlet of a calciner operating at full-load with a net thermal power input of $100 \mathrm{MWth}$, in which 100\% calcination is achieved (Figure 3).

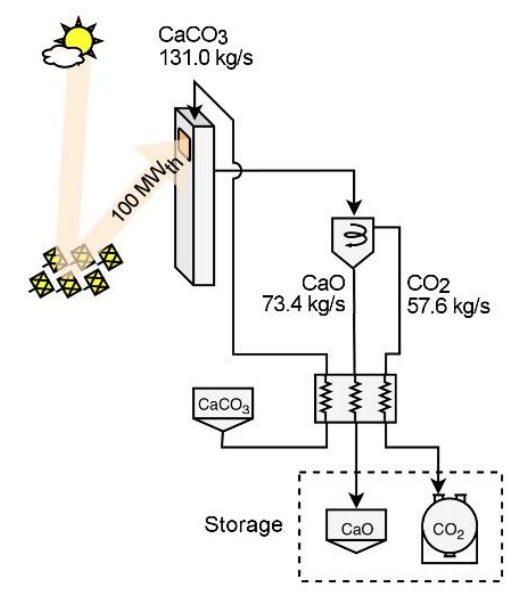

Figure 3. Conceptual design of the energy storage process using a calciner in a solar power plant.

The average sorbent conversion in the carbonator is assumed to be $13.3 \%$, which corresponds to a material with a maximum residual conversion of about $9-12 \%$ that has been cycled $20-30$ times in average [37]. Moreover, the solids are assumed to have a particle diameter of 60 microns. Thus, the outlet mass flows will be $17.31 \mathrm{~kg} / \mathrm{s}$ of $\mathrm{CaCO}_{3}, 63.71 \mathrm{~kg} / \mathrm{s}$ of $\mathrm{CaO}$, and $50.00 \mathrm{~kg} / \mathrm{s}$ of $\mathrm{CO}_{2}$. The gas is separated from the solids, cooled in order to be recirculated to the carbonator using a blower, and heated again prior entering the carbonator; thus, $86.7 \%$ of the inlet $\mathrm{CO}_{2}$ circulates in a closed loop. The solid stream is cooled and stored to be later used in the calciner, where the $100 \mathrm{MWth}$ solar input is invested to heat the material from room temperature and to calcine the $100 \%$ of the $\mathrm{CaCO}_{3}$ present in the solids mixture.

Three different configurations (Figure 4) have been proposed and modelled to assess the behavior of the carbonation reaction, the required size of the carbonator and the potential of thermochemical energy storage.

- Configuration 1 is a single reactor where the total inlet mass flows are introduced. This setup aims for simplicity of operation and reduction of costs. 
- Configuration 2 consists of two carbonation reactors operating in parallel and inlet mass flows are equally diverted among them. The objective is to reduce the released heat in each carbonator and the required sizes of carbonators.

- Configuration 3 operates two carbonator reactors connected in series with intermediate cooling. The objective is to avoid the inhibition of the reaction along the carbonators. The sensible heat is removed through exchangers specifically designed for that purpose instead of through the helical coils around the carbonators.

Heat will be evacuated from three main sources: (i) the carbonation reactors through the four superficial helical coiled heat exchangers, $\dot{Q}_{c}$, (ii) the solid-solid heat exchanger at the outlet of the reactor, $\dot{Q}_{S}$, and (iii) the gas-gas heat exchanger at the outlet of the reactor, $\dot{Q}_{\mathrm{CO} 2}$.
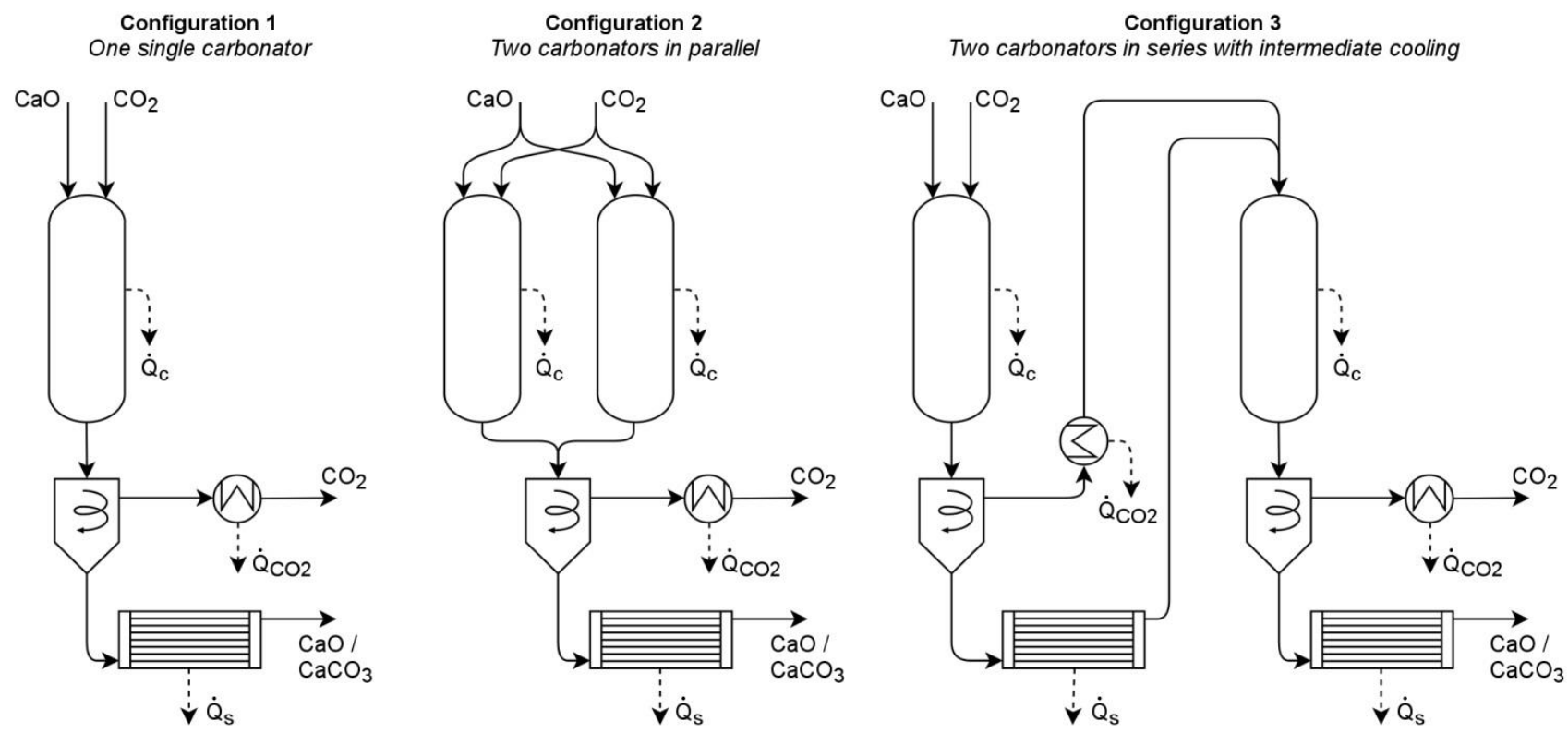

Figure 4. Case studies for the three proposed carbonator configurations.

\section{Methodology}

To analyze the temperature, conversion, residence times and heat exchanges of each configuration, a number of simulations has been performed. The carbonator model considers the specific geometry, heat transfer mechanisms and calcination kinetics; thus, obtaining the temperature profiles along the carbonator under 
non-isothermal conditions. The model considers steady-state since the target of the study is the assessment of size and configuration of a single component and the information provided by this steady approach is sufficient. It has been implemented in Engineering Equation Solver - EES software. The residence time of the gas in the carbonator is calculated considering 1D plug flow. The entraining downflow velocity for the solids is calculated through the terminal velocity and the gas velocity. The governing equations were solved using a numerical mesh with 100 discrete 1-D elements to obtain axial profiles for the main operating variables.

\subsection{Carbonation kinetic model}

The kinetic model considered in the calculations was published and validated by Ortiz et al [37]. Thus, the carbonation reaction is described by (1), which gives the conversion of $\mathrm{CaO}$ as a function of time and reaction rate:

$$
X(t)=\frac{X_{k}}{1+e^{-r\left(t-t_{0}\right)}}
$$

where $X_{k}$ is the conversion at the end of the reaction controlled phase (assumed as 0.133 for highly sintered $\mathrm{CaO}$ ) and $t_{0}$ the time taken to reach a $X_{k} / 2$ conversion. The reaction rate, $r$, is given by (2) as a function of temperature and $\mathrm{CO}_{2}$ partial pressure:

$$
r=a_{2} \cdot e^{\left(-\frac{E_{2}}{\mathcal{R} T}\right)} \cdot\left(\frac{P}{P_{e q}}-1\right) \cdot\left(\frac{1}{\frac{P}{P_{e q}}+e^{\left(\Delta S_{2}^{0} / \mathcal{R}\right)} e^{\left(-\Delta H_{2}^{0} / \mathcal{R} T_{s}\right)}}\right)
$$

where $E_{2}$ is $20 \mathrm{~kJ} / \mathrm{mol}, \Delta S_{2}^{0}$ is $-68 \mathrm{~J} / \mathrm{mol} \cdot \mathrm{K}$ and $\Delta H_{2}^{0}$ is $-160 \mathrm{~kJ} / \mathrm{mol}$. Besides, $P_{e q}=\mathcal{A} \cdot \exp (-a / T)$, where $\mathcal{A}$ is 4.083.107 atm, and $a$ is $20474 \mathrm{~K}$. The results derived from the implementation of this kinetic model estimates the mole flow of each component as a function of time. Therefore, the residence time of solid flowing down through the reactor is required in order to characterize the dimensions of the carbonator. 


\subsection{Residence time for the solids}

The residence time of solids limits the time of interaction between the solid and the gas. Equation (3) may be applied to calculate the downward velocity of single particles, $v_{s}$, for Reynolds below 2 and small particle sizes [42]:

$$
v_{s}=v_{s, i} \cdot e^{-b t_{s}}+\left(v_{g}+v_{t}\right) \cdot\left(1-e^{-b t_{s}}\right)
$$

where $v_{s, i}$ is the initial velocity of the solid, $v_{g}$ is the velocity of the gas phase (volumetric flow divided by the cross section), and $v_{t}$ is the terminal settling velocity of the particle in a static fluid. The parameter $b$, and the velocity $v_{t}$ are given by (4) and (5):

$$
\begin{gathered}
b=\frac{18 \mu}{\rho_{s} d_{p}^{2}} \\
v_{t}=\frac{\left(\rho_{s}-\rho_{g}\right) d_{p}^{2} g}{18 \mu}
\end{gathered}
$$

where $\mu$ is the viscosity of the gas, $\rho_{s}$ is the density of the solid, $\rho_{g}$ is the density of the gas, $d_{p}$ is the diameter of the solid particles, and $g$ the gravity.

After the integration of Equation (3), the obtained expression provides the carbonation reactor length as a function of the residence time of the solids (6).

$$
L=\int_{0}^{t_{s, L}} v_{s} d t_{s}=\frac{v_{s, i}}{b}\left(1-e^{-b t_{s}}\right)+\left(v_{g}+v_{t}\right) \cdot\left(t_{s}-\frac{1-e^{-b t_{s}}}{b}\right)
$$

It can be assumed that $v_{g}$ and $\mu$ are constants in the interval of integration for the case of study. Thus, the integrated expression can be directly solved to compute the residence time of the solid as a function of the length, what will allow the calculation of the mole flows profile along the reactor as a function of the axial position.

The integration of equation 6 is performed for each slice of the discretized reactor. Thus, the length of integration is the length of the slice. The parameters $b, v_{g}$ and $v_{t}$ are calculated at the specific temperature 
and pressure of the gas in each slice. Therefore, the total residence time of the particles takes into account the variation in temperature, pressure and gas volume along the reactor.

\subsection{Plug flow model (1D) for the gas phase}

The gas phase inside the reactor have a parabolic velocity profile (laminar flow). For the sake of simplicity, our model assumes to follow a plug flow behavior, in the sense that the fluid of a slice is not mixed with the fluid of any other slice ahead or behind (flat velocity profile). Also, this assumption implies that the residence time in the reactor is the same for all elements of fluid. The residence time of the gas is given by (7) considering the plug flow model (1D).

$$
t_{g}=\int_{0}^{L} \frac{\pi r_{i n}^{2}}{\dot{V}} d L
$$

where $r_{\text {in }}$ is the inner radius of the carbonator, $\dot{V}$ is the volumetric flow rate, and $L$ the carbonator length. Moreover, $\dot{V}$ is the product of the gas velocity multiplied by the cross-sectional area of the reactor. The crosssectional area is corrected by subtracting the area occupied by the solids. The variation in the effective crosssectional area along the reactor may be neglected as $\mathrm{CaCO}_{3}$ is produced when $\mathrm{CaO}$ is consumed.

Besides, it is assumed that the pressure inside the reactor remains constant at 1.7 bar. Hence, the volumetric flow rate is given by (8), according to the ideal gas law:

$$
\dot{V}_{L 2}=\frac{\left(1-X_{L 2}\right) \cdot T_{L 2}}{T_{L 1}} \dot{V}_{L 1}
$$

The residence time of the gas, through a length $L_{i}$ in which $\dot{V}_{L i}$ can be considered constant will be $t_{g(L 1)}=L_{i}$. $S_{\text {eff }} / \dot{V}_{L i}$

\subsection{Heat transfer model}

In this section, the heat transfer methodology is described. First, the energy balance inside the reactor is presented (exothermal reaction). Then it is described the heat transfer from gas and solids to the walls of the reactor. The calculation of both the radiative and convective terms is described in detail. Lastly, the energy 
balance of the cooling fluid is presented, considering the cooling fluid at the same temperature than the outer wall of the reactor.

The carbonator is covered by a cooling jacket which consists of four helical coiled heat exchangers. To compute the heat transfer from the cloud of gas and particles to the cooling fluid, an energy balance inside the reactor is firstly computed for each slice of reactor (from length $L_{i-1}$ to length $L_{i}$ ) by (9):

$$
\sum_{j} C p_{j} \cdot \dot{n}_{j, L_{i}} \cdot\left(T_{L_{i}}-T_{L_{i-1}}\right)=-\Delta H_{r} \cdot\left(\dot{n}_{C a C O 3, L_{i}}-\dot{n}_{C a C O 3, L_{i-1}}\right)-\dot{q}_{L_{i}}^{\prime} \cdot\left(L_{i}-L_{i-1}\right)
$$

where $C p_{j}$ and $\dot{n}_{j}$, are the specific heat and mole flow of component $j$, respectively, $T$ is the temperature of the cloud of gas and particles (assumed to be homogeneous inside the carbonator), $\Delta H_{r}$ is the enthalpy of reaction $(-178 \mathrm{~kJ} / \mathrm{mol})$, and $\dot{q}_{L_{i}}^{\prime}$ is the heat flow throughout the inside wall of the carbonator per unit of length. The heat flow through the wall accounts for radiation and convection terms, in the form of (10):

$$
\begin{gathered}
\dot{q}_{L_{i}}^{\prime}=\dot{q}_{r a d, L_{i}}^{\prime}+\dot{q}_{c o n v, L_{i}}^{\prime} \\
\dot{q}_{r a d, L_{i}}^{\prime}=\frac{\varepsilon_{w}}{\alpha_{g+p}+\varepsilon_{w}-\alpha_{g+p} \cdot \varepsilon_{w}} \cdot \sigma \cdot\left(\varepsilon_{g+p} \cdot T_{L_{i}}^{4}-\alpha_{g+p} \cdot T_{i w, L_{i}}^{4}\right) \cdot 2 \pi r \\
\dot{q}_{c o n v, L_{i}}^{\prime}=h_{g, L_{i}} \cdot\left(T_{L_{i}}-T_{i w, L_{i}}\right) \cdot 2 \pi r
\end{gathered}
$$

where $\alpha_{g+p}$ and $\varepsilon_{g+p}$ are the absorptivity and emissivity of the gas-particle mixture, $\varepsilon_{w}$ the emissivity of the carbonator wall, $\sigma$ is the Stefan-Boltzmann constant, $T_{i w}$ is the temperature of the inner wall of the carbonator, $r$ the inner radius of the carbonator, and $h_{g}$ the convective coefficient.

The model for the calculation of the absorptivity and emissivity of the gas-particle mixture is borne out of the VDI Heat Atlas, Part K [43]. The total emissivity of a gas-particle mixture can be described as

$$
\varepsilon_{g+p}=(1-\beta)\left(\frac{1-\exp \left(-\Phi_{e m i, g+p}\right)}{1+\beta \exp \left(-\Phi_{e m i, g+p}\right)}\right)
$$

where 


$$
\begin{gathered}
\gamma=\sqrt{1+\frac{2 \bar{Q}_{b s c}}{\bar{Q}_{a b s}}} \\
\beta=\frac{\gamma-1}{\gamma+1} \\
\Phi_{e m i, g+p}=\left(\bar{Q}_{a b s} A L_{p}+K_{e m i, g}\right) l_{m b} \gamma
\end{gathered}
$$

In a similar manner the absorptivity can be calculated:

$$
\alpha_{g+p}=(1-\beta)\left(\frac{1-\exp \left(-\Phi_{a b s, g+p}\right)}{1+\beta \exp \left(-\Phi_{a b s, g+p}\right)}\right)
$$

where

$$
\Phi_{a b s, g+p}=\left(\bar{Q}_{a b s} A L_{p}+K_{a b s, g}\right) l_{m b} \gamma
$$

$L_{p}$ is the particle loading, in $\mathrm{kg} / \mathrm{m}^{3}$, the parameter $l_{m b}$ is the mean beam length of radiation within the relevant geometry and $A$ is the specific surface area of the particles.

The determination of particle absorption and scattering coefficients $\bar{Q}_{a b s}$ and $\bar{Q}_{b s c}$ is taken from the limestone's data graph included in the Heat Atlas. The mean particle diameter $d_{p}$ may be measured experimentally, or calculated from the surface area and density of the particles by equation (19). In this article it is assumed 60 micron for particle's diameter.

$$
d_{p}=\frac{3}{2 \rho_{p} A}
$$

The gas absorption and scattering coefficients are defined as

$$
\begin{aligned}
& K_{e m i, g}=-\frac{\ln \left(1-\varepsilon_{g}\right)}{l_{m b}} \\
& K_{a b s, g}=-\frac{\ln \left(1-A_{v}\right)}{l_{m b}}
\end{aligned}
$$

where $\varepsilon_{g}$ is the emissivity of the gas and $A_{v}$ is the absorptance. The values of $\varepsilon_{g}$ varies with pressure, optical thickness and temperature are provided in [43]. The absorptance $A_{v}$ is a function of the wall and gas temperatures and the emissivity of the gas: 


$$
A_{v}=f_{p, C O_{2}}\left(\frac{T_{g}}{T_{w}}\right)^{0.65} \varepsilon_{g}
$$

The parameter $f_{p, \mathrm{CO}_{2}}$ is a pressure correction factor that at 1.0 bar total pressure is equal to 1.000 , and at 1.7 bar is equal to 1.018.

Besides, the model for the calculation of the convective coefficient between the $\mathrm{CO}_{2}$ and the wall is borne out of 'Heat Transfer' by Nellis G and Klein S [44], and follows (23) to (27):

$$
\begin{gathered}
h_{g, L_{i}}=\frac{N u_{L i} \cdot k_{L i}}{2 r} \\
N u_{L_{i}}=3.66+\frac{\left(0.049+\frac{0.020}{P r_{L i}}\right) \cdot G z_{L i}^{1.12}}{1+0.065 \cdot G z_{L i}^{0.7}} \\
\operatorname{Pr}_{L i}=\frac{C p_{L i} \cdot \mu_{L i}}{k_{L i}} \\
G z_{L i}=\frac{R e_{L i} \cdot P r_{L i}}{L / 2 r} \\
R e_{L i}=\frac{4 \cdot \dot{m}_{L i}}{\pi \cdot 2 r \cdot \mu_{L i}}
\end{gathered}
$$

where $N u$ is the Nusselt number, $k$ the thermal conductivity, $P r$ the Prandtl number, $G z$ the Graetz number, $\mu$ the viscosity, $R e$ the Reynolds number, and $\dot{m}$ the mass flow. The convective coefficient is calculated for each slice in which the reactor is discretized, at the corresponding temperature and pressure.

The temperature of the outer wall of the carbonator, $T_{o w}$, is computed by the formula of heat conduction through a tube wall (28):

$$
\begin{gathered}
\dot{q}_{L_{i}}^{\prime}=\frac{T_{i w, L_{i}}-T_{o w, L_{i}}}{R_{\text {tube }} \cdot L_{i}} \\
R_{\text {tube }}=\frac{\ln \left(\frac{r_{\text {out }}}{r}\right)}{2 \pi \cdot k_{\text {tube }} \cdot L_{i}}
\end{gathered}
$$

where $R_{\text {tube }}$ is the thermal resistance of the carbonator tube, $r_{\text {out }}$ the outer radius of the carbonator, and $k_{\text {tube }}$ the thermal conductivity of the carbonator tube $(0.025 \mathrm{~kW} / \mathrm{m} \cdot \mathrm{K})$. 
Since the convective coefficient inside the helical pipe is several orders of magnitude greater than inside the carbonator, the temperature of the carbonator outer wall is assumed to be equal to the temperature of the cooling fluid inside the helical pipe for each cell. Thus, the following energy balance on the cooling fluid is computed (30):

$$
C p_{c f} \cdot \dot{n}_{c f} \cdot\left(T_{o w, L_{i}-1}-T_{o w, L_{i}}\right)=\dot{q}_{L_{i}}^{\prime} \cdot\left(L_{i}-L_{i-1}\right)
$$

where $C p_{c f}$ and $\dot{n}_{c f}$ are the specific heat and the mole flow of the cooling fluid. It should be noted that (30) is valid for heat exchangers in which the cooling fluid flows from bottom to top (counter-current, HEX sections 1 and 2), and therefore it is heated from position $L_{i}$ to $L_{i-1}$, with the heat produced inside the carbonator from position $L_{i-1}$ to $L_{i}$. In case of evaluating a co-current heat exchanger (HEX sections 3 and 4), the energy balance is given by (31), where the cooling fluid flows from top to bottom.

$$
C p_{c f} \cdot \dot{n}_{c f} \cdot\left(T_{o w, L_{i}}-T_{o w, L_{i}-1}\right)=\dot{q}_{L_{i}}^{\prime} \cdot\left(L_{i}-L_{i-1}\right)
$$

Thus, the temperature along the carbonator can be computed by knowing the initial temperature of the cooling fluid.

\section{Results and discussion}

In this section, the methodology described above is applied to three potential carbonator schemes (Figure 4). The study assesses the size requirements and technical performance of each configuration. As stated, the scale of the system is $100 \mathrm{MWth}$ of useful thermal power inside the calciner.

Moreover, in subsection 4.1 the model is compared with experimental results from literature, and in subsection 4.2 the influence of the particle diameter is presented.

\subsection{Comparison of model results with experimental data from literature}

The experimental results of an entrained flow carbonator from Plou et al. [45] are used to validate the model presented in this article. The reactor of Plou et al. is a 24 meter spiral-shaped stainless steel tube, with an external diameter of 3/8" (inner diameter of $7.54 \mathrm{~mm}$ ). The gas velocity used during the experiments avoids saltation conditions within the entrained flow regime (i.e., avoids falling of particles). The reactor is kept 
isothermal at $650^{\circ} \mathrm{C}$ along the whole path. Three different materials were analysed: two types of high-purity calcined lime and one cement raw meal. The results of the material tagged as "Lime \#1" are used in this study for comparison as it has a similar value of $X_{k}$ (i.e., conversion at the end of the reaction controlled phase) and $t_{0}$ (i.e., the time taken to reach a $X_{k} / 2$ conversion) than the material assumed in the simulations of this study. Lime \#1 has $X_{k}=0.10$ and $t_{0}$ about 2 seconds, while the material used in our simulations has $X_{k}=0.13$ and $t_{0}=1.5$ seconds. These are typical conversions of highly deactivated materials.

Figure 5 shows the $\mathrm{CO}_{2}$ capture efficiency, which is defined as the $\mathrm{CO}_{2}$ captured versus the maximum possible according to the equilibrium. The experiments were carried out with a gas velocity of $13.5 \mathrm{~m} / \mathrm{s}$ at $650{ }^{\circ} \mathrm{C}$ and 1 bar (about $2.4 \cdot 10^{-4} \mathrm{~kg} / \mathrm{s}$ ). The gas is composed of $10 \% \mathrm{CO}_{2}$ and $90 \%$ air. The mass ratio between the solid and the gas was varied between 0.125 and 0.400 by modifying the mass of $\mathrm{CaO}$ entered in the reactor.

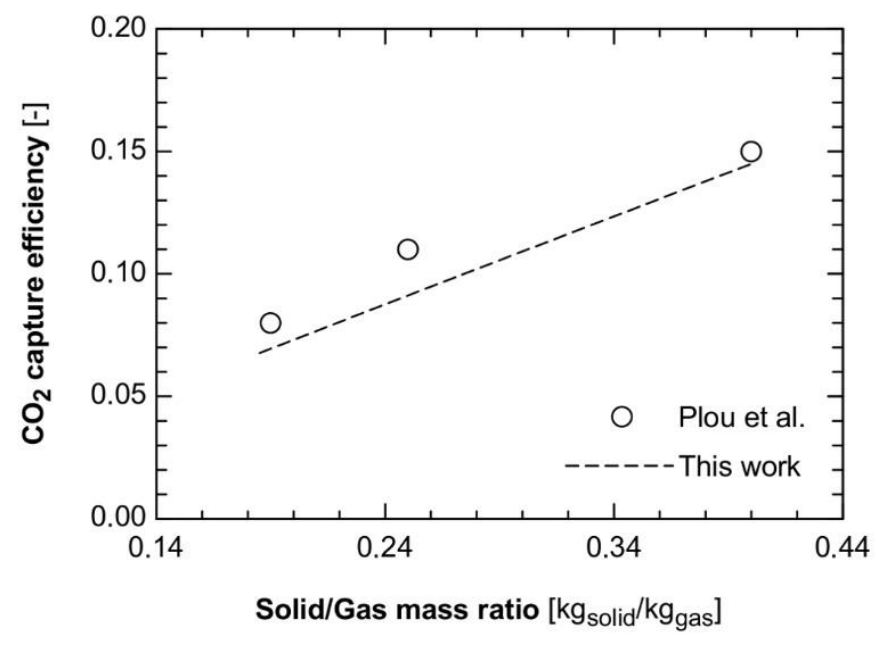

Figure 5. $\mathrm{CO}_{2}$ capture efficiency achieved in the entrained flow reactor of Plou et al. [45] and in the simulations of this study under the same setup, as a function of the solid/gas mass ratio.

The results show a good agreement with the experiments of Plou et al. for Lime \#1. The residence time they measured is 1.8 seconds, while the residence time calculated by the simulation is 1.78 seconds for the gas and 1.77 seconds for the solids. 


\subsection{Influence of the diameter of particles in the residence time of the solids}

One of the main differences that arise when using calcium looping as thermochemical energy storage instead of using it as carbon capture method is the size of particles needed. In case of CaL-CSP applications, the proper diameter of particles is of tens of microns $(\sim 60 \mu \mathrm{m})$. This size of particles may remarkably modify the residence time of the solids inside the carbonator with respect to other applications such as CaL for carbon capture $(\sim 300 \mu \mathrm{m})$ (Figure 6). With 60 microns as base case scenario, a variation in the diameter of $[-42 \%,+32 \%]$ (i.e., particles between $35 \mu \mathrm{m}$ and $79 \mu \mathrm{m}$ ) could be assumed keeping the variation of the residence time of the solids below $\pm 5 \%$, for a carbonator diameter of 7 meters. In the case of carbonator has a lower diameter, the allowable span of variation in the size of the particles increases, as can be seen in Figure 6.

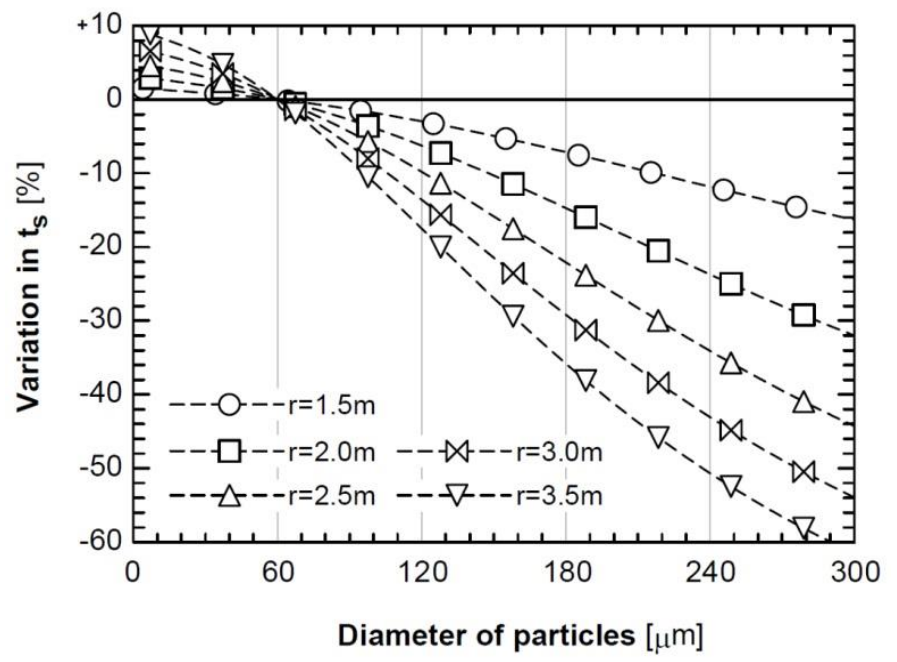

Figure 6. Variation of the residence time of the solids vs. the diameter of the particles.

\subsection{Ideal case - Isothermal reactor}

The ideal case of an isothermal reactor is presented in this section to contextualize the reactor under study. The reactor is kept at $800^{\circ} \mathrm{C}$ (inlet temperature of reactants). The heat removal required to operate under this condition is presented in Figure 7. An ideal heat exchanger should accomplish with this heat removal profile along the reactor (Figure 7, left). The total heat removal is presented in the right graph of Figure 7, which also corresponds with the evolution of the reaction. 

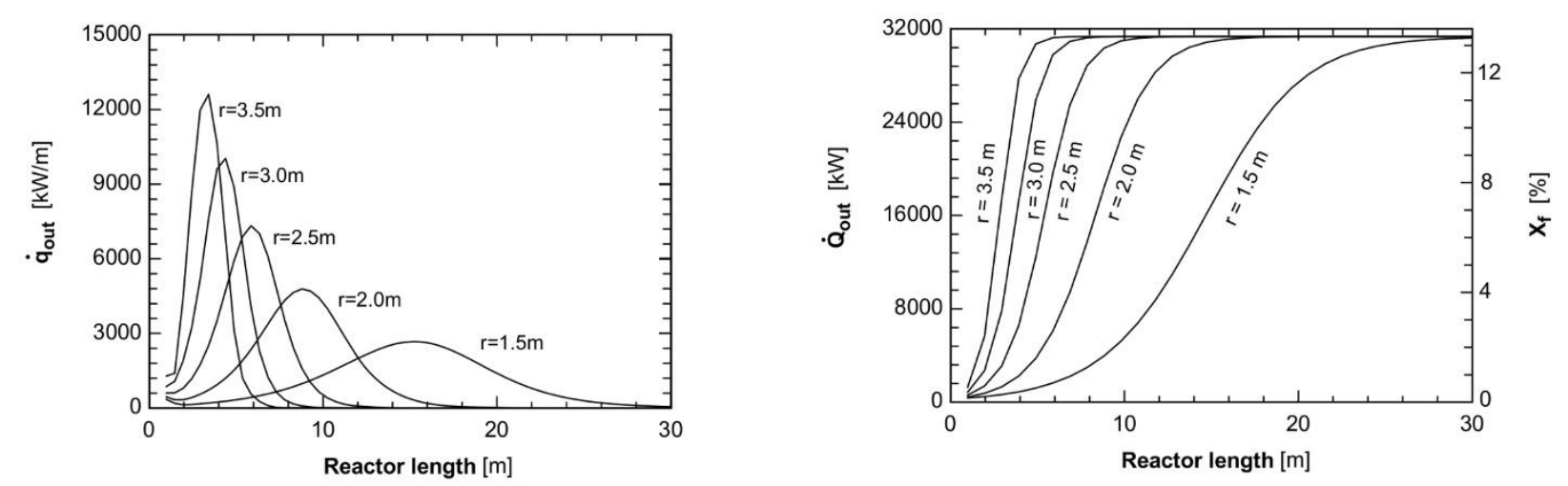

Figure 7. Heat removal profile (left) and total removed thermal power for isothermal operation (right) vs. reactor length and internal radius dimensions.

These graphs can be used to understand how far from are the solution proposed from the ideal system.

\subsection{Configuration 1: One single carbonator}

The first configuration aims at performing the carbonation in one single reactor. However, the lengths required to achieve high conversions may be not reasonable because of the large mass flows of reactants (Figure 8). When diameters between $7 \mathrm{~m}$ and $4 \mathrm{~m}$ are considered, carbonators that are between $37 \mathrm{~m}$ and $56 \mathrm{~m}$ in length are required to reach $12 \%$ conversion. Moreover, to increase this value up to $13.2 \%$ (i.e., the $99 \%$ of the achievable conversion) it must be lengthen the reactor about $15-17 \mathrm{~m}$. Thus, for a carbonator of $7 \mathrm{~m}$ in diameter, a total length of $52 \mathrm{~m}$ would be needed.

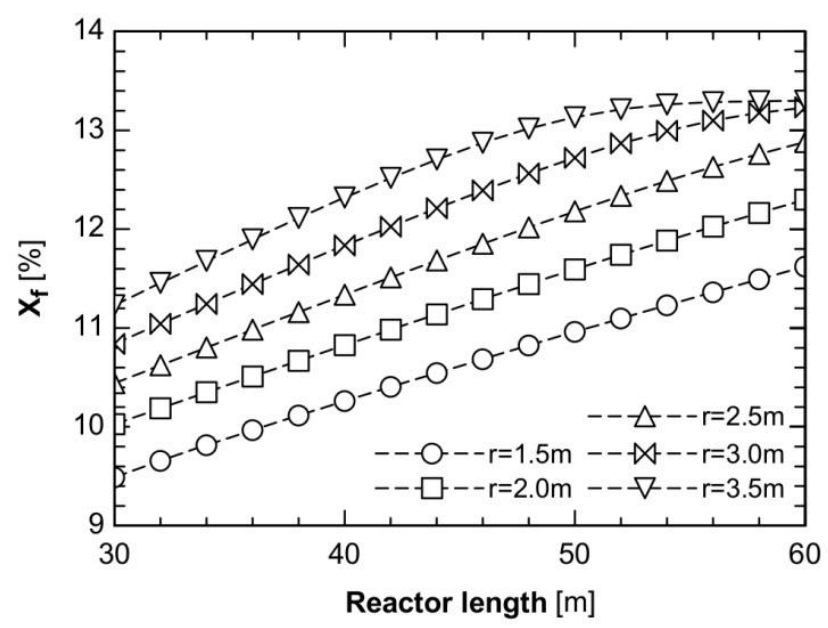

Figure 8. Final conversion vs. reactor's total length and internal radius dimensions (Configuration 1). 
The main reason for the requirement of excessively long reactors is the insufficient heat removal. The unremoved thermal power rapidly heats the mass flows inside the reactor up to the equilibrium temperature (Figure 9). Hence, after the first meters the conversion growths slowly and linearly with the heat removal. Within this regime, the conversion only increases between 0.076 and 0.116 percentage points per meter of reactor depending on its diameter.

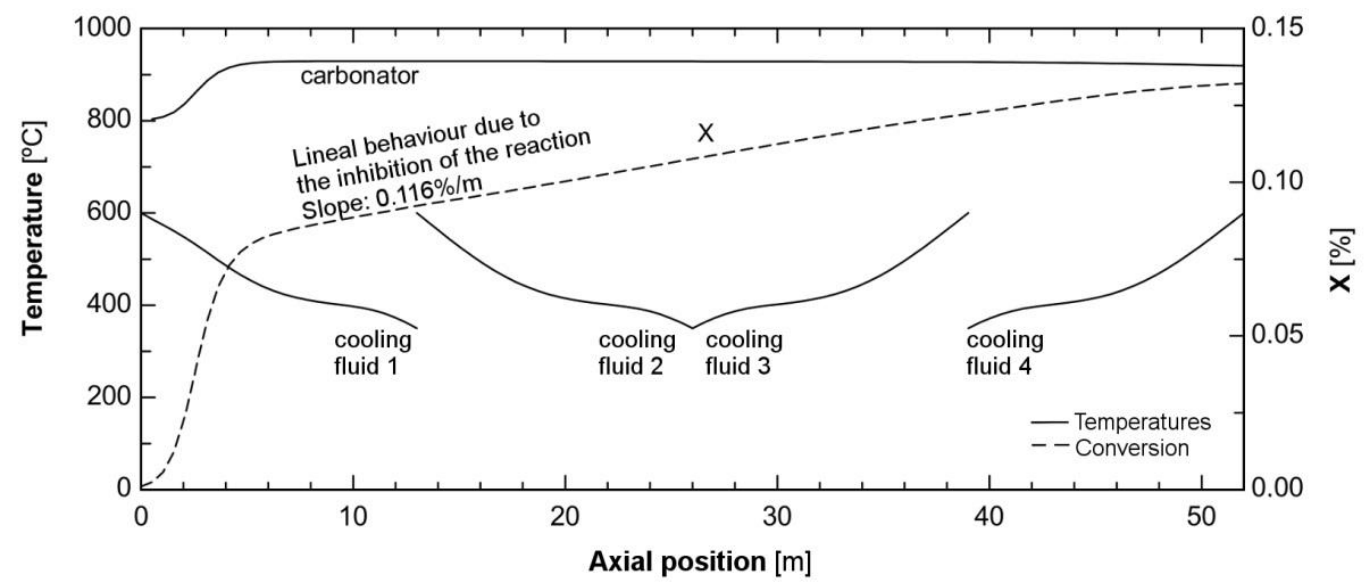

Figure 9. Temperatures and conversion profiles vs. axial position ( $L=52 \mathrm{~m}, \mathrm{r}=3.5 \mathrm{~m}$, Configuration 1$)$.

The exothermal power produced during the carbonation is linearly dependent on the reactants conversion. Thus, the major release of heat takes place at the beginning of the reactor. In this study (system scale of 100 MWth of net solar input in the calciner), the total released thermal power due to carbonation is $28.4 \mathrm{MW}$ when the conversion reaches $12 \%$, while it increases to $31.1 \mathrm{MW}$ at $13.2 \%$ conversions (Figure 10). However, the removed thermal power only amounts to the $35.2 \%-36.6 \%$ of the cited value in reactors sized for $12 \%$ conversion (i.e., $10.0-10.9 \mathrm{MW}$ ). This percentage increases to about the $45.0 \%-51.8 \%$ (i.e., $14.0-16.1 \mathrm{MW}$ ) for reactors long enough to reach $13.2 \%$ conversion. The heat removed by the cooling system continues growing linearly for greater lengths even though the carbonation reaction stops, since the reactor temperature is reduced. This effect is partially noticeable in Figure 9, at the end of the reactor. 

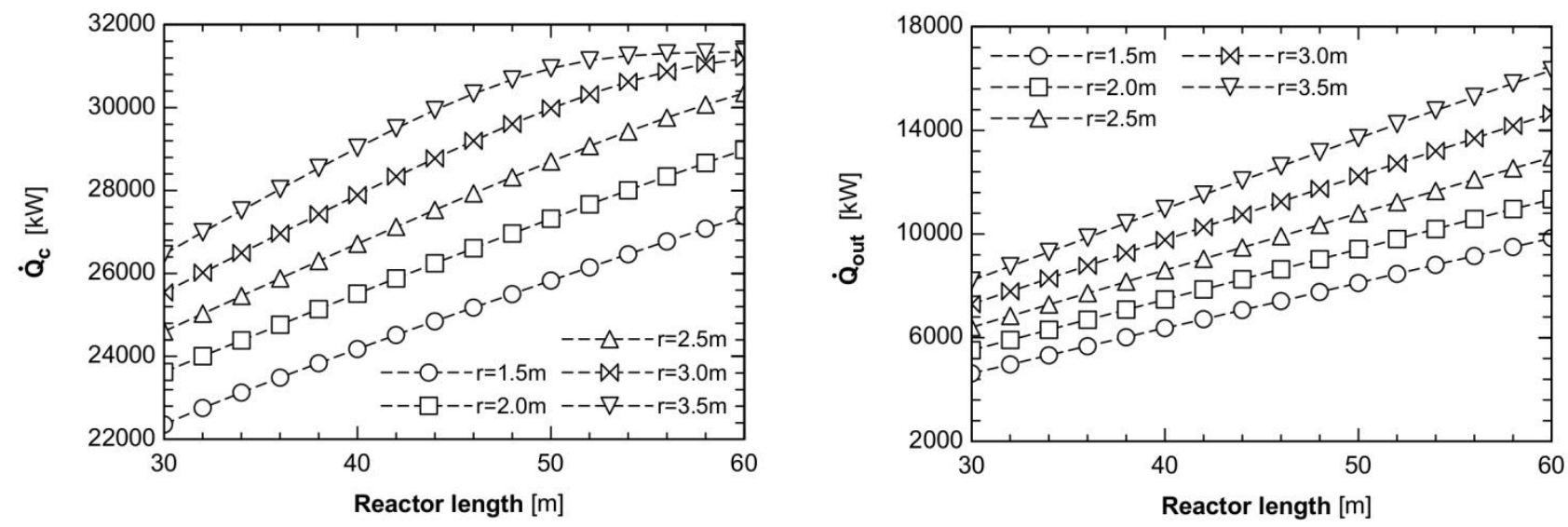

Figure 10. Total exothermal power from carbonation (left) and total removed thermal power by cooling fluid (right) vs. reactor's total length and internal radius dimensions (Configuration 1).

In order to recover the rest of the heat, the mixture of gas and solids should be cooled after exiting the carbonator. This could be performed by separating both phases in a cyclone and passing them through gasgas and gas-solid heat exchangers to heat an extra amount of supercritical steam (from $350{ }^{\circ} \mathrm{C}$ to $600^{\circ} \mathrm{C}$ ), as depicted in Figure 4. In this study, the $\mathrm{CO}_{2}$ is cooled down to $800{ }^{\circ} \mathrm{C}$ and recirculated to the carbonator inlet. Therefore, the available thermal power from this gas ranges from $7.8 \mathrm{MW}$ to $8.2 \mathrm{MW}$ at reactors sized for $12 \%$ conversions (Figure 11). This represents the $27 \%-29 \%$ of the exothermal heat coming from the reaction. Besides, the solids are cooled to 450 으, which provides an available thermal power between $36.8 \mathrm{MW}$ and 38.3 MW, for reactors sized to reach $12 \%$ reactant's conversion (Figure 11 ).
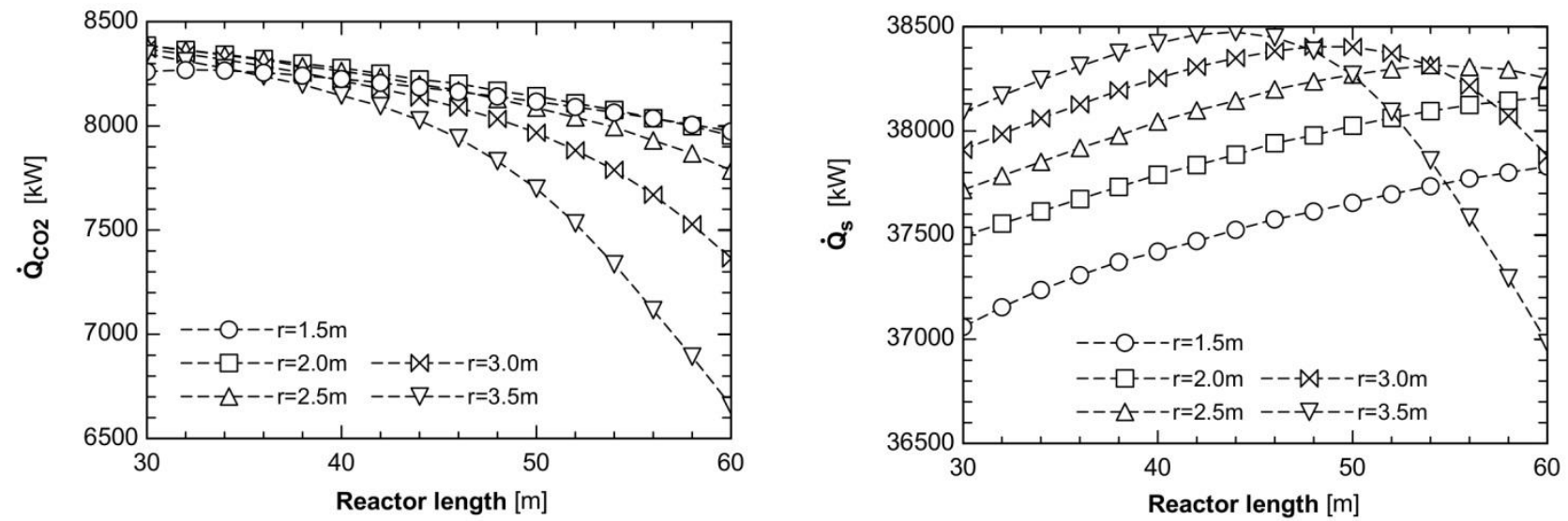
Figure 11. Available thermal power from $\mathrm{CO}_{2}$ (left) and solids (right) vs. reactor total length and internal radius dimensions (Configuration 1 ).

In summary, the total recovered thermal power amounts to $55.5-56.5 \mathrm{MW}$ (i.e., $56 \%$ of the net solar input in the calciner) for reactors that achieve $12 \%$ conversion. This values increases to $58.3-59.6 \mathrm{MW}$ when reactors are sized for $13.2 \%$ conversion, which is not a significant increase considering the additional length required.

\subsection{Configuration 2: Two carbonators in parallel}

The second proposed configuration presents two carbonator reactors operating in parallel where inlet mass flowrates of reactants are equally diverted among them. The aim is to assess heat transfer mechanisms when flowrates are reduced and the subsequent influence on the required lengths and diameters to achieve acceptable sorbent conversion. Conversions above $12 \%$ are achieved for carbonator lengths between $20 \mathrm{~m}$ and $39 \mathrm{~m}$ for diameters between $7 \mathrm{~m}$ and $3 \mathrm{~m}$. The lengths required to achieve these conversions are still high, but become more reasonable for reactors of 6 and 7 meters in diameter (Figure 12). If the maximum sorbent capacity for a cycled material is to be reached, $13.3 \%$, the carbonator length must be increased in about 10 meters; i.e. a $7 \mathrm{~m}$ diameter carbonator would require a total carbonator length of $30 \mathrm{~m}$.

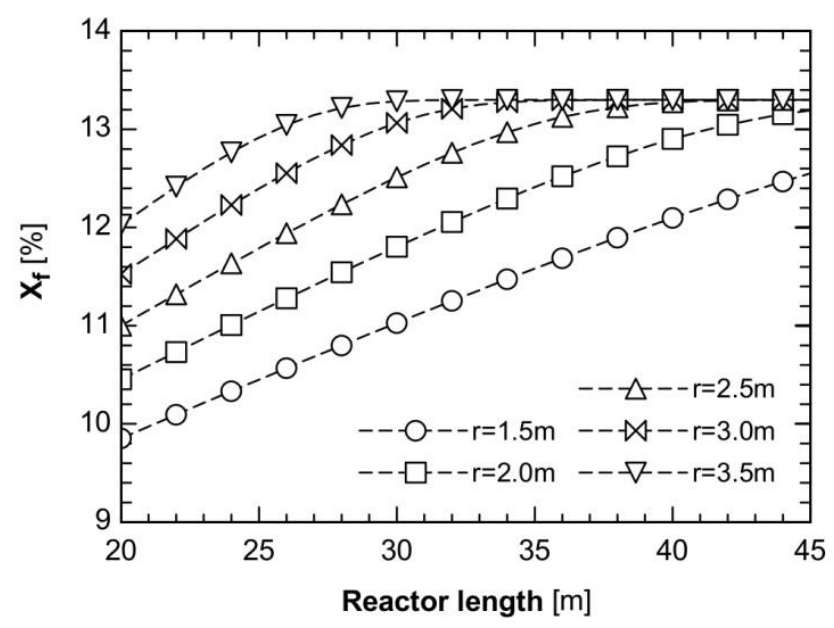

Figure 12. Final conversion vs. reactor total length and internal radius dimensions (Configuration 2). 
As already mentioned, the heat released during the carbonation reaction follows a linear relation with the sorbent conversion. During the first meters of the carbonator, the larger amount of heat is released since the reaction rate is enhanced by high reactants concentrations and moderate temperatures. The total heat from carbonation amounts to $14.1 \mathrm{MW}$ when the sorbent conversion is $12 \%$. This value is increased up to $15.6 \mathrm{MW}$ if $13.2 \%$ conversion is achieved (Figure 13 ).
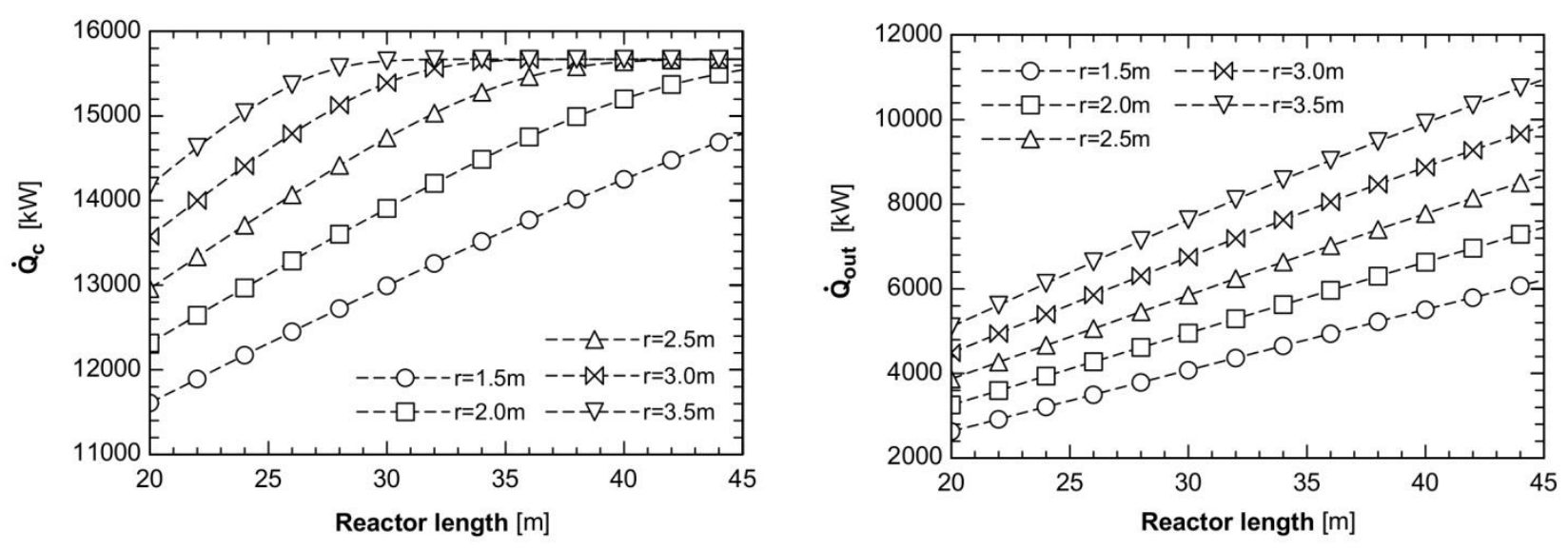

Figure 13. Total exothermal power from carbonation (left) and total removed thermal power by cooling fluid (right) vs reactor total length and internal radius dimensions (Configuration 2).

The recovered heat considering the design of the cooling system and the profile of heat released by carbonation amounts to the $36.0 \%-38.0 \%$ of the carbonation heat in reactors sized for $12 \%$ conversion (i.e., $5.1-5.4 \mathrm{MW}$ ). The recovered heat is increased up to $7.1-7.8 \mathrm{MW}$ which corresponds to a $45.8-50.4 \%$ of the carbonation heat released when sorbent conversion in the reactor achieves $13.2 \%$. As mentioned in section 4.3, the heat recovered with the cooling fluid is increased for larger lengths of the carbonator even when maximum carbonation conversion has been reached. This is due to the gradual cooling of the carbonator in the last meters. Figure 13 illustrates this phenomenon and the value of recovered heat as a function of reactor dimensions.

The amount of heat which cannot be removed from the carbonator rapidly heats the mass flows inside the reactor up to the equilibrium temperature and the carbonation reaction is favoured in the three initial meters 
of the carbonator (Figure 14). After this first stage, the conversion rate dramatically diminishes and the conversion growth becomes slow and linear with heat removal. The specific conversion increment during this lineal stage ranges between 0.122 and 0.220 percentage points per meter of reactor. Again, specific heat removal per unit length is insufficient to increase reaction rate and long reactors are required to control the residence time and the conversion of the sorbent.

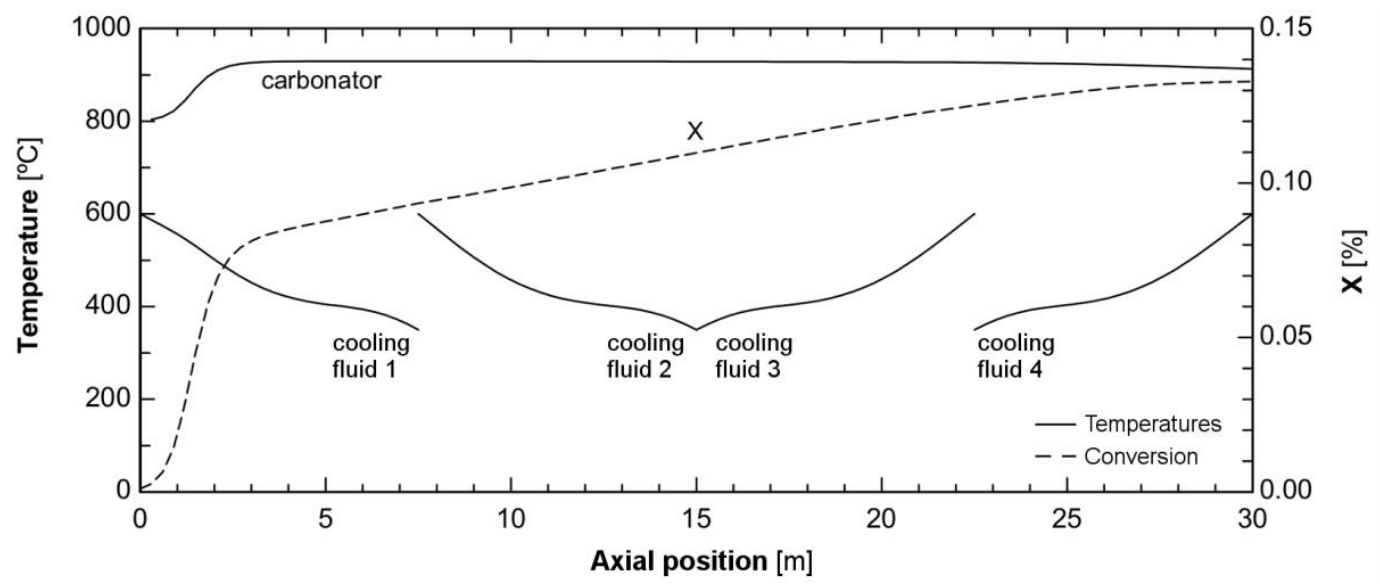

Figure 14. Temperatures and conversion profiles vs. axial position ( $\mathrm{L}=30 \mathrm{~m}, \mathrm{r}=3.5 \mathrm{~m}$, Configuration 2$)$

The heat not recovered in the carbonator itself through the cooling system leaves the reactor with the mixture of gas and solids as sensible heat. This energy can be recovered by means of cooling these streams after exiting the carbonator. Solid and gas are separated in two cyclones and, then, each stream is directed to a gas-gas and a gas-solid heat exchanger to increase the temperature of an extra amount of supercritical steam. $\mathrm{CO}_{2}$ stream is cooled down to $800{ }^{\circ} \mathrm{C}$ and the available heat in the gas-gas heat exchanger ranges from $4.0 \mathrm{MW}$ to 4.1 MW for reactors with $12 \%$ final sorbent conversion (Figure 15) which represents the $28.1 \%-29.0 \%$ of the carbonation reaction. Solids are cooled down to $450^{\circ} \mathrm{C}$ and the available heat in the gas-solid heat exchanger varies from 17.9 MW to $18.1 \mathrm{MW}$, for reactors with a $12 \%$ of solid sorbent conversion (Figure 15). 

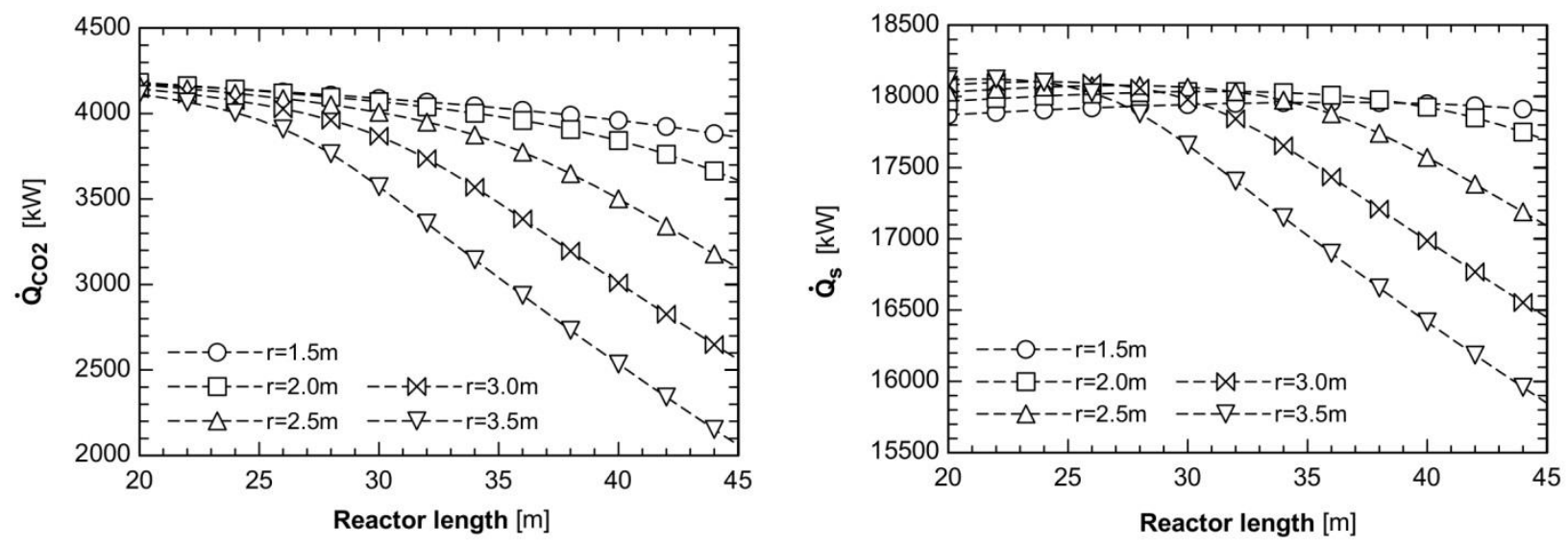

Figure 15. Available thermal power from $\mathrm{CO}_{2}$ (left) and solids (right) vs. reactor's total length and internal radius dimensions (Configuration 2 ).

The overall results obtained for this second configuration (Table 1), e.g. available heats from carbonator and heat exchangers and sorbent conversion, are near to those obtained for Configuration 1 . Also, the dimensions of the two reactors in parallel are of the same order of magnitude when added and compared to the single reactor configuration.

Table 1. Length required, and removed thermal power by cooling fluid and available thermal power in the products in Configuration 1 and 2 (carbonators sized for $12 \%$ conversion).

\begin{tabular}{|l|l|r|r|r|r|r|r|r|r|}
\hline & & \multicolumn{4}{|c|}{ Configuration 1 } & \multicolumn{4}{|c|}{ Configuration 2 (only 1 reactor) } \\
\hline$r[\mathrm{~m}]$ & $X_{f}[\%]$ & $L[\mathrm{~m}]$ & $\dot{Q}_{\text {out }}[\mathrm{MW}]$ & $\dot{Q}_{\mathrm{CO} 2}[\mathrm{MW}]$ & $\dot{Q}_{s}[\mathrm{MW}]$ & $L[\mathrm{~m}]$ & $\dot{Q}_{\text {out }}[\mathrm{MW}]$ & $\dot{Q}_{\mathrm{CO2}}[\mathrm{MW}]$ & $\dot{Q}_{s}[\mathrm{MW}]$ \\
\hline 2.0 & 0.12 & 56 & 10.6 & 8.0 & 38.1 & 32 & 5.3 & 4.0 & 18.0 \\
\hline 2.5 & 0.12 & 48 & 10.4 & 8.1 & 38.2 & 27 & 5.3 & 4.1 & 18.1 \\
\hline 3.0 & 0.12 & 42 & 10.3 & 8.2 & 38.3 & 23 & 5.2 & 4.1 & 18.1 \\
\hline 3.5 & 0.12 & 37 & 10.1 & 8.2 & 38.3 & 20 & 5.1 & 4.1 & 18.1 \\
\hline
\end{tabular}

\subsection{Configuration 3: Two carbonators in series with intermediate cooling}

The third configuration presents two reactors operating in series with a cooling stage between them (Figure 2). The aim is to carbonate the material only during the rapid regime in which reaction is not yet inhibited. To 
do so, the reactors are lengthened until the increase in conversion per unit length $(\Delta X / L)$ decreases to a lower limit. The selected threshold corresponds to 1.5 times the slope of the linear regime that can be observed in inhibited carbonators.

For instance, when the carbonator diameter is $7 \mathrm{~m}$, the slope of the linear regime is $0.116 \% / \mathrm{m}$ (see Figure 6), so the threshold slope is set at $0.174 \% / \mathrm{m}$ for Configuration 3 . Hence, the first reactor in series is shortened to $5.84 \mathrm{~m}$, where this threshold slope is reached. The conversion of the reactants at this point is $8.4 \%$, the released thermal power from carbonation is $19.7 \mathrm{MW}$, and the removed thermal power by the supercritical steam just accounts for the $7.6 \%$ of this heat (Table 2 ). The helical coiled heat exchangers are such inefficient because the reactor's length became shorter than the diameter. Therefore, it may be concluded that great diameters are unsuitable for this kind of layout.

Table 2. Sizes of carbonators, final conversion and thermal heats for Configuration 3.

\begin{tabular}{|c|c|c|c|c|c|c|c|c|c|c|c|c|c|}
\hline & $\begin{array}{l}\text { Sizing } \\
\text { criterion }\end{array}$ & First st & & & & $\begin{array}{l}\text { Interm } \\
\text { coolin }\end{array}$ & & Secor & d stage & & & $\begin{array}{l}\text { Produ } \\
\text { coolin }\end{array}$ & \\
\hline $\begin{array}{l}r \\
{[\mathrm{~m}]}\end{array}$ & $\begin{array}{l}\text { Min. } \Delta X / L \\
{[\% / \mathrm{m}]}\end{array}$ & $\begin{array}{l}L \\
{[\mathrm{~m}]}\end{array}$ & $\begin{array}{l}X_{f} \\
{[\%]}\end{array}$ & $\begin{array}{l}\dot{Q}_{c} \\
{[\mathrm{MW}]}\end{array}$ & $\begin{array}{l}\dot{Q}_{\text {out }} \\
{[\mathrm{MW}]}\end{array}$ & $\begin{array}{l}\dot{Q}_{\mathrm{CO} 2} \\
{[\mathrm{MW}]}\end{array}$ & $\begin{array}{l}\dot{Q}_{s} \\
{[\mathrm{MW}]}\end{array}$ & $\begin{array}{l}L \\
{[\mathrm{~m}]}\end{array}$ & $\begin{array}{l}X_{f} \\
{[\%]}\end{array}$ & $\begin{array}{l}\dot{Q}_{c} \\
{[\mathrm{MW}]}\end{array}$ & $\begin{array}{l}\dot{Q}_{\text {out }} \\
{[\mathrm{MW}]}\end{array}$ & $\begin{array}{l}\dot{Q}_{\mathrm{CO} 2} \\
{[\mathrm{MW}]}\end{array}$ & $\begin{array}{l}\dot{Q}_{s} \\
{[\mathrm{MW}]}\end{array}$ \\
\hline 1.5 & 0.114 & 26.18 & 9.1 & 21.5 & 4.0 & 8.2 & 9.2 & 8.52 & 12.9 & 8.4 & 1.3 & 3.4 & 30.8 \\
\hline 2.0 & 0.135 & 15.40 & 8.7 & 20.5 & 2.6 & 8.4 & 9.4 & 6.05 & 13.0 & 9.6 & 1.0 & 4.1 & 31.6 \\
\hline 2.5 & 0.145 & 10.56 & 8.6 & 20.2 & 2.1 & 8.5 & 9.5 & 4.55 & 13.1 & 10.1 & 0.9 & 4.4 & 32.0 \\
\hline 3.0 & 0.162 & 7.67 & 8.4 & 19.9 & 1.7 & 8.6 & 9.5 & 3.53 & 13.1 & 10.4 & 0.8 & 4.6 & 32.2 \\
\hline 3.5 & 0.174 & 5.84 & 8.4 & 19.7 & 1.5 & 8.6 & 9.6 & 2.84 & 13.2 & 10.6 & 0.7 & 4.8 & 32.4 \\
\hline
\end{tabular}

In the case of 3 meters of diameter, the first reactor would be $26 \mathrm{~m}$ in length ( $L / D$ ratio of 8.7) under the sizing criterion established. After exiting the first stage, the conversion reaches $9.1 \%$, leading to $21.5 \mathrm{MW}$ of exothermal power coming from carbonation (Figure 16, up). The $18.6 \%$ of this heat is properly evacuated by the supercritical steam along the reactor. Moreover, the intermediate cooling may recover $8.2 \mathrm{MW}$ and 9.2 MW thanks to the reduction of the gas and solids temperature down to $800{ }^{\circ} \mathrm{C}$, respectively, before entering the second reactor. Then, by applying the same sizing criterion to the second reactor, the length required is 
8.52 meters ( $L / D$ ratio of 2.8 ), leading to a $12.9 \%$ final conversion (Figure 16 , down). In total, the overall useful thermal power accounting for both carbonators and cooling stages is $56.9 \mathrm{MW}$ (i.e., $56.9 \%$ of the solar thermal power input inside the calciner). This value is higher than in Configuration 1 when considering the same final conversion. Besides, the dimensions required in the reactor are feasible from a technical point of view, contrarily to Configuration 1.
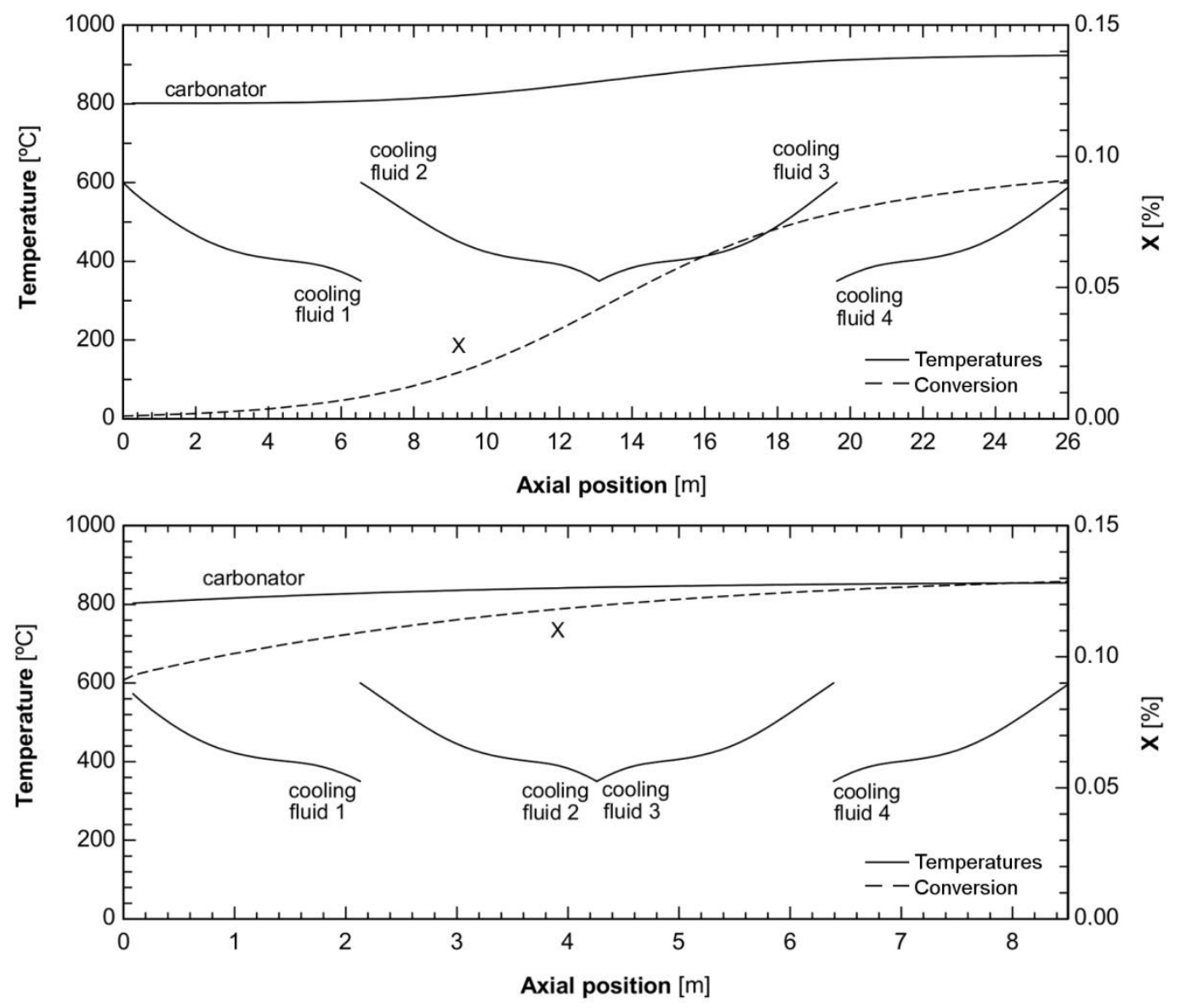

Figure 16. Temperatures and conversion profiles (first stage: up, second stage: down) vs. axial position ( $r=1.5$ m, Configuration 3)

Hence, Configuration 3 shows the best performance since it avoids the inhibition of the reaction. Moreover, this configuration is close to the isothermal case, so it presents similar requirements in reactor volume (about $78 \mathrm{~m}^{3}$ against the $54 \mathrm{~m}^{3}$ for the ideal isothermal case). It represents $80 \%$ less volume than the first and second configuration for the same performance. One of the best options is an arrangement of two reactors of 3 meters in diameter of 26.1 and 8.5 meters in length, leading to a final conversion of $12.9 \%$. 


\section{Conclusions}

A potential commercial-scale carbonator is presented and modelled in the frame of a new concentrated solar power plant. The design of a carbonator reactor for a specific CaL-CSP application has not been addressed yet in detail in literature. The main novelty of this study is the assessment of the conceptual design of a CaL-CSP carbonator and the influence of different parameters. The internal design of the carbonator is a co-current entrained flow reactor while refrigeration is carried out by means of four helical coiled heat exchangers. Two of them in counter-current flow and two of them in co-flow with respect to internal carbonator flow. The overall $\mathrm{CaO}$ and $\mathrm{CO}_{2}$ inlet mass flow rates are $73.41 \mathrm{~kg} / \mathrm{s}$ and $57.62 \mathrm{~kg} / \mathrm{s}$, respectively, which correspond to solar thermal power of $100 \mathrm{MWth}$ inside the calciner. Different configurations, lengths and diameters for the carbonator scheme are analysed, as well as the corresponding available heat. The three studied configurations are (i) a single reactor where the total inlet mass flows are introduced, (ii) two carbonation reactors operating in parallel and inlet mass flows are equally diverted among them and (iii) two carbonator reactors connected in series with intermediate cooling. The cooling fluid is supercritical steam that enters the heat exchangers at

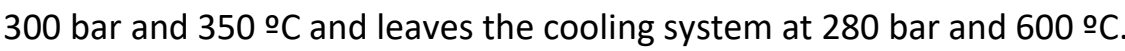

The steady-state model accounted for reactor geometry, heat transfer and carbonation kinetics. The temperature profiles along the carbonator under non-isothermal conditions may be obtained as a result. In order to reach enough accuracy in the results obtained from the model, the total length of the reactor is discretized in 100 slices.

Results obtained for all the three configurations show that the heat released from carbonation reaction cannot be properly evacuated. Thus, reactants and products inside the reactor are easily heated up to the equilibrium temperature in the first meters of the carbonator. Other potential cooling configurations to improve the heat removal could be studied in further works, such as internal coils with variable surface area.

In the two first configurations, from the axial position in which equilibrium temperature is reached onwards, the conversion slowly and linearly increases as the heat is removed. For Configuration 1, a single reactor with $52 \mathrm{~m}$ length and $7 \mathrm{~m}$ in diameter leads to final conversion of $13.2 \%$ and a heat recovery of $14 \mathrm{MW}$ from the 
four helical coiled heat exchangers. The required mass flows of supercritical steam are $1.85 \mathrm{~kg} / \mathrm{s}, 1.97 \mathrm{~kg} / \mathrm{s}$, $1.94 \mathrm{~kg} / \mathrm{s}$ and $1.96 \mathrm{~kg} / \mathrm{s}$. If sensible heat from the outlet stream is considered, $7.5 \mathrm{MW}$ can be recovered from the gaseous $\mathrm{CO}_{2}$ and $38.1 \mathrm{MW}$ from the solids mixture. The total available heat invested in the production of supercritical steam is $59.6 \mathrm{MW}$, what represents a $59.6 \%$ of the thermal power used inside the calciner.

In Configuration 2, reactors of 30 meters in length and 7 meters in diameter are required to reach the maximum conversion of the material (13.3\%). In practice, the operation with two carbonators in parallel allows to shorten the length of reactors by half compared to Configuration 1 . Nevertheless, the reaction is also inhibited after the reactants traverse a few meters, limiting the specific conversion increments between 0.122 and 0.220 percentage points per meter of reactor. This leads to an inefficient carbonation process and reactors that are still excessively large.

Configuration 3 has the best performance since it allows avoiding the linear regime in which reaction is inhibited (close to the isothermal case). The results show that it is feasible to reach $12.9 \%$ conversion with two reactors of 3 meters in diameter that are only 26.1 and 8.5 meters in length, thanks to the intermediate cooling. If the reactors have 4 meters of diameter, the lengths required to reach $13 \%$ conversion diminish to 15.4 and 6.0 meters. Besides, the thermal power recovered is about $57 \mathrm{MW}$ in both cases (i.e., the $57 \%$ of the thermal power that entered inside the calciner). It is worth to mention that the present study considers the same diameter for the two reactors in series in Configuration 3. Further work is necessary for optimization, by assessing different diameters in the first and second carbonators in order to improve the performance and costs. Other option could be increasing the number of stages in Configuration 3 , in order to resemble better the temperature profile to the isothermal behaviour.

\section{Declaration of Competing Interest}

The authors declare no potential conflicts of interest with respect to the research, authorship, and/or publication of this article. 


\section{Acknowledgements}

The research leading to these results has received funding from the European Union's Horizon 2020 research and innovation programme under grant agreement [No 727348], project SOCRATCES. This work has also been supported by the Government of Aragon (Research Group DGA T46_17R) and co-financed by FEDER 20142020 "Construyendo Europa desde Aragón".

\section{Nomenclature}

Variable

\begin{tabular}{|l|l|l|}
\hline$a_{2}$ & {$[1 / \mathrm{s}]$} & pre-exponential factor \\
\hline$a$ & {$[\mathrm{~K}]$} & fitting parameter for the equilibrium pressure \\
\hline$A$ & {$\left[\mathrm{~m}^{2} / \mathrm{kg}\right]$} & specific projection area of the dispersed particles \\
\hline$A_{v}$ & {$[-]$} & geometry-dependent absorptance of the gas body \\
\hline $\mathcal{A}$ & {$[\mathrm{atm}]$} & pre-exponential factor \\
\hline$b$ & {$[1 / \mathrm{s}]$} & calculation parameter \\
\hline$C p$ & {$[\mathrm{~kJ} /(\mathrm{kmol} \cdot \mathrm{K})]$} & specific heat \\
\hline$d$ & {$[\mathrm{~m}]$} & diameter \\
\hline$E_{2}$ & {$[\mathrm{~kJ} / \mathrm{mol}]$} & carbonation activation energy \\
\hline$f_{p}$ & {$[-]$} & pressure correction factor \\
\hline$g$ & {$\left[\mathrm{~m} / \mathrm{s}^{2}\right]$} & gravity \\
\hline$G z$ & {$[-]$} & Graetz number \\
\hline$h$ & {$\left[\mathrm{~kW} /\left(\mathrm{m}^{2} \cdot \mathrm{K}\right)\right]$} & convective heat transfer coefficient \\
\hline$k$ & {$[\mathrm{~kW} /(\mathrm{m} \cdot \mathrm{K})]$} & thermal conductivity \\
\hline$K$ & {$[1 / \mathrm{m}]$} & emission or absorption coefficient of the gas phase \\
\hline$l_{m b}$ & {$[\mathrm{~m}]$} & mean beam length \\
\hline$L$ & {$[\mathrm{~m}]$} & length \\
\hline$L_{p}$ & {$\left[\mathrm{~kg} / \mathrm{m}^{3}\right]$} & particle load at operation conditions \\
\hline$\dot{m}$ & {$[\mathrm{~kg} / \mathrm{s}]$} & mass flow rate \\
\hline$\dot{n}$ & {$[\mathrm{kmol} / \mathrm{s}]$} & mole flow rate \\
\hline$N u$ & {$[-]$} & Nusselt number \\
\hline$P$ & {$[\mathrm{bar}]$} & pressure \\
\hline$P r$ & {$[-]$} & Prandtl number \\
\hline$\dot{q}^{\prime}$ & {$[\mathrm{kW} / \mathrm{m}]$} & heat flow per unit of length \\
\hline $\bar{Q}$ & {$[-]$} & mean relative absorption or backscattering efficiency of a particle \\
\hline$r$ & {$[1 / \mathrm{s}]$} & reaction rate \\
\hline$r$ & {$[\mathrm{~m}]$} & radius \\
\hline$R$ & {$[\mathrm{~K} / \mathrm{kW}]$} & thermal resistance \\
\hline$R e$ & {$[-]$} & Reynolds number \\
\hline $\mathcal{R}$ & {$[\mathrm{kJ} /(\mathrm{kmol} \cdot \mathrm{K})]$} & ideal gas constant \\
\hline$S_{e f f}$ & {$\left[\mathrm{~m}{ }^{2}\right]$} & effective cross-sectional area of reactor \\
\hline$t$ & {$[\mathrm{~s}]$} & reacting time or residence time \\
\hline$t_{0}$ & {$[\mathrm{~s}]$} & time to reach half of residual conversion \\
\hline$T$ & {$[\mathrm{~K}]$} & temperature \\
\hline & & \\
\hline$R$ & & \\
\hline & & \\
\hline & & \\
\hline & &
\end{tabular}




\begin{tabular}{|c|c|c|}
\hline$v$ & {$[\mathrm{~m} / \mathrm{s}]$} & velocity \\
\hline V & {$\left[\mathrm{m}^{3}\right]$} & volume \\
\hline$\dot{V}$ & {$\left[\mathrm{~m}^{3} / \mathrm{s}\right]$} & volumetric flow rate \\
\hline$X$ & {$[-]$} & conversion \\
\hline$X_{k}$ & {$[-]$} & residual conversion \\
\hline$\Delta S_{2}^{0}$ & {$[\mathrm{~J} /(\mathrm{mol} \cdot \mathrm{K})]$} & carbonation entropy change \\
\hline$\Delta H_{2}^{0}$ & {$[\mathrm{~kJ} / \mathrm{mol}]$} & standard enthalpy change of carbonation \\
\hline$\Delta H_{r}$ & {$[\mathrm{~kJ} / \mathrm{kmol}]$} & enthalpy of carbonation \\
\hline$\alpha$ & {$[-]$} & absorptivity \\
\hline$\beta$ & {$[-]$} & calculation parameter \\
\hline$\gamma$ & {$[-]$} & calculation parameter \\
\hline$\varepsilon$ & {$[-]$} & emissivity \\
\hline$\mu$ & {$[\mathrm{kg} /(\mathrm{m} \cdot \mathrm{s})]$} & viscosity \\
\hline$\rho$ & {$\left[\mathrm{kg} / \mathrm{m}^{3}\right]$} & density \\
\hline$\sigma$ & {$\left[\mathrm{kW} /\left(\mathrm{m}^{2} \cdot \mathrm{K}^{4}\right)\right]$} & Stefan-Boltzmann constant \\
\hline$\Phi$ & {$[-]$} & optical thickness for the gas solid dispersion \\
\hline
\end{tabular}

Subscript and Superscript

\begin{tabular}{|l|l|}
\hline$a b s$ & absorption \\
\hline$b s c$ & backscattering \\
\hline$c$ & carbonator \\
\hline$c f$ & cooling fluid \\
\hline$c o n v$ & convection \\
\hline$e m i$ & emission \\
\hline$e q$ & equilibrium \\
\hline$f$ & final \\
\hline$g$ & gas \\
\hline$i$ & initial value or discretization index for axial position \\
\hline in & inner \\
\hline iw & inner wall \\
\hline$j$ & component j \\
\hline$L$ & covered length \\
\hline out & outer radius or diameter \\
\hline ow & outer wall \\
\hline$p$ & particle \\
\hline rad & radiation \\
\hline$s$ & solid \\
\hline$t$ & terminal velocity \\
\hline tube & carbonator's tube \\
\hline$w$ & wall \\
\hline
\end{tabular}

\section{References}

[1] NASA Goddard Institute for Space Studies. GISS Surface Temperature Analysis (GISTEMP) 2019. 
https://data.giss.nasa.gov/gistemp/ (accessed December 15, 2019).

[2] Lenssen NJL, Schmidt GA, Hansen JE, Menne MJ, Persin A, Ruedy R, et al. Improvements in the GISTEMP Uncertainty Model. J Geophys Res Atmos 2019;124:6307-26. doi:10.1029/2018JD029522.

[3] Intergovernmental Panel on Climate Change. Climate change 2014 - Synthesis report. 2014. doi:10.1017/CBO9781107415324.

[4] Scripps Institution of Oceanography. The keeling curve 2017.

https://scripps.ucsd.edu/programs/keelingcurve/ (accessed December 15, 2019).

[5] Anderson TR, Hawkins E, Jones PD. CO2, the greenhouse effect and global warming: from the pioneering work of Arrhenius and Callendar to today's Earth System Models. Endeavour 2016;40:178-87. doi:10.1016/j.endeavour.2016.07.002.

[6] International Energy Agency. CO2 emissions from fuel combustion. 2015. doi:10.1787/co2_fuel-2015en.

[7] European Union. Directive (EU) 2018/2001 of the European Parliament and of the Council on the promotion of the use of energy from renewable sources. Off J Eur Union 2018;2018:1-128.

[8] Capros P, Vita A De, Tasios N, Siskos P, Kannavou M, Petropoulos A, et al. EU Reference Scenario 2016: Energy, transport and GHG emissions. Trends to 2050. European Union; 2016. doi:10.2833/9127.

[9] Alva G, Lin Y, Fang G. An overview of thermal energy storage systems. Energy 2018;144:341-78. doi:10.1016/j.energy.2017.12.037.

[10] Kearney D, Kelly B, Herrmann U, Cable R, Pacheco J, Mahoney R, et al. Engineering aspects of a molten salt heat transfer fluid in a trough solar field. Energy 2004;29:861-70. doi:10.1016/S03605442(03)00191-9.

[11] Kuravi S, Trahan J, Goswami DY, Rahman MM, Stefanakos EK. Thermal energy storage technologies and systems for concentrating solar power plants 2013. doi:10.1016/j.pecs.2013.02.001.

[12] Prieto C, Cooper P, Fernández AI, Cabeza LF. Review of technology: Thermochemical energy storage for concentrated solar power plants. Renew Sustain Energy Rev 2016;60:909-29. doi:10.1016/j.rser.2015.12.364.

[13] Luzzi A, Lovegrove K, Filippi E, Fricker H, Schmitz-goeb M, Chandapillai M, et al. Techno-economic analysis of a $10 \mathrm{MWe}$ solar thermal power plant using ammonia-based thermochemical energy storage. Fuel Energy Abstr 1999;40:403. doi:10.1016/S0140-6701(99)99040-9.

[14] Kyaw K, Matsuda H HM. Applicability of carbonation/decarbonation reactions to high-temperature thermal energy storage and temperature upgrading. J Chem Eng Jpn 1996;29:119-25.

[15] Chacartegui R, Alovisio A, Ortiz C, Valverde JM, Verda V, Becerra JA. Thermochemical energy storage of concentrated solar power by integration of the calcium looping process and a $\mathrm{CO} 2$ power cycle. Appl Energy 2016;173:589-605. doi:10.1016/j.apenergy.2016.04.053.

[16] Romeo LM, Abanades JC, Escosa JM, Paño J, Giménez A, Sánchez-Biezma A, et al. Oxyfuel carbonation/calcination cycle for low cost $\mathrm{CO} 2$ capture in existing power plants. Energy Convers Manag 2008;49. doi:10.1016/j.enconman.2008.03.022.

[17] Lisbona P, Martínez A, Lara Y, Romeo LM. Integration of carbonate CO2 capture cycle and coal-fired power plants. A comparative study for different sorbents. Energy and Fuels 2010;24:728-36. doi:10.1021/ef900740p. 
[18] Perejón A, Romeo LM, Lara Y, Lisbona P, Martínez A, Valverde JM. The Calcium-Looping technology for $\mathrm{CO} 2$ capture: On the important roles of energy integration and sorbent behavior. Appl Energy 2016;162. doi:10.1016/j.apenergy.2015.10.121.

[19] Ortiz C, Chacartegui R, Valverde JM, Alovisio A, Becerra JA. Power cycles integration in concentrated solar power plants with energy storage based on calcium looping. Energy Convers Manag 2017;149:815-29. doi:10.1016/j.enconman.2017.03.029.

[20] Bayon A, Bader R, Jafarian M, Fedunik-Hofman L, Sun Y, Hinkley J, et al. Techno-economic assessment of solid-gas thermochemical energy storage systems for solar thermal power applications. Energy 2018;149:473-84. doi:10.1016/j.energy.2017.11.084.

[21] Rodriguez N, Alonso M, Grasa G, Abanades JC. Heat requirements in a calciner of CaCO3 integrated in a CO2 capture system using $\mathrm{CaO} 2008 ; 138: 148-54$. doi:10.1016/j.cej.2007.06.005.

[22] Luo L, Tsoukpoe KEN, Liu H, Pierre N Le. A review on long-term sorption solar energy storage 2009;13:2385-96. doi:10.1016/j.rser.2009.05.008.

[23] Khosa AA, Xu T, Xia BQ, Yan J, Zhao CY. Technological challenges and industrial applications of $\mathrm{CaCO} / \mathrm{CaO}$ based thermal energy storage system - A review. Sol Energy 2019;193:618-36. doi:10.1016/j.solener.2019.10.003.

[24] Chen X, Zhang Z, Qi C, Ling X, Peng H. State of the art on the high-temperature thermochemical energy storage systems. Energy Convers Manag 2018;177:792-815.

doi:10.1016/j.enconman.2018.10.011.

[25] Sunku Prasad J, Muthukumar P, Desai F, Basu DN, Rahman MM. A critical review of hightemperature reversible thermochemical energy storage systems. Appl Energy 2019;254:113733. doi:10.1016/j.apenergy.2019.113733.

[26] Reich L, Yue L, Bader R, Lipiński W. Towards solar thermochemical carbon dioxide capture via calcium oxide looping: A review. Aerosol Air Qual Res 2014;14:500-14. doi:10.4209/aaqr.2013.05.0169.

[27] Rhodes NR, Barde A, Randhir K, Li L, Hahn DW, Mei R, et al. Solar Thermochemical Energy Storage Through Carbonation Cycles of SrCO 3 / SrO Supported on SrZrO 3 2015:3793-8. doi:10.1002/cssc.201501023.

[28] Ortiz C, Chacartegui R, Valverde JM, Becerra JA. A new integration model of the calcium looping technology into coal fired power plants for CO2 capture. Appl Energy 2016;169:408-20. doi:10.1016/j.apenergy.2016.02.050.

[29] Edwards SEB, Materić V. Calcium looping in solar power generation plants. Sol Energy 2012. doi:10.1016/j.solener.2012.05.019.

[30] Benitez-Guerrero M, Valverde JM, Sanchez-Jimenez PE, Perejon A, Perez-Maqueda LA. Multicycle activity of natural $\mathrm{CaCO} 3$ minerals for thermochemical energy storage in Concentrated Solar Power plants. Sol Energy 2017;153:188-99. doi:10.1016/j.solener.2017.05.068.

[31] Da Y, Xuan Y, Teng L, Zhang K, Liu X, Ding Y. Calcium-based composites for direct solar-thermal conversion and thermochemical energy storage. Chem Eng J 2020;382:122815. doi:10.1016/j.cej.2019.122815.

[32] André L, Abanades S. Evaluation and performances comparison of calcium, strontium and barium carbonates during calcination/carbonation reactions for solar thermochemical energy storage. J Energy Storage 2017;13:193-205. doi:10.1016/j.est.2017.07.014.

[33] Tregambi C, Salatino P, Solimene R, Montagnaro F. An experimental characterization of Calcium 
Looping integrated with concentrated solar power. Chem Eng J 2018;331:794-802. doi:10.1016/j.cej.2017.08.068.

[34] Sarrión B, Perejón A, Sánchez-Jiménez PE, Pérez-Maqueda LA, Valverde JM. Role of calcium looping conditions on the performance of natural and synthetic Ca-based materials for energy storage. J CO2 Util 2018;28:374-84. doi:10.1016/j.jcou.2018.10.018.

[35] Zsembinszki G, Sole A, Barreneche C, Prieto C, Fernández AI, Cabeza LF. Review of reactors with potential use in thermochemical energy storage in concentrated solar power plants. Energies 2018;11. doi:10.3390/en11092358.

[36] Nikulshina V, Gebald C, Steinfeld A. CO2 capture from atmospheric air via consecutive CaOcarbonation and $\mathrm{CaCO} 3$-calcination cycles in a fluidized-bed solar reactor. Chem Eng J 2009;146:2448. doi:10.1016/j.cej.2008.06.005.

[37] Ortiz C, Valverde JM, Chacartegui R, Perez-Maqueda LA. Carbonation of Limestone Derived CaO for Thermochemical Energy Storage: From Kinetics to Process Integration in Concentrating Solar Plants. ACS Sustain Chem Eng 2018;6:6404-17. doi:10.1021/acssuschemeng.8b00199.

[38] Romano MC. Modeling the carbonator of a Ca-looping process for $\mathrm{CO} 2$ capture from power plant flue gas. Chem Eng Sci 2012;69:257-69. doi:10.1016/J.CES.2011.10.041.

[39] Ortiz C, Chacartegui R, Valverde JM, Becerra JA, Perez-Maqueda LA. A new model of the carbonator reactor in the calcium looping technology for post-combustion CO2 capture. Fuel 2015;160:328-38. doi:10.1016/J.FUEL.2015.07.095.

[40] Alovisio A, Chacartegui R, Ortiz C, Valverde JM, Verda V. Optimizing the CSP-Calcium Looping integration for Thermochemical Energy Storage. Energy Convers Manag 2017;136:85-98. doi:10.1016/j.enconman.2016.12.093.

[41] Espatolero S, Romeo LM, Cortés C. Efficiency improvement strategies for the feedwater heaters network designing in supercritical coal-fired power plants 2014. doi:10.1016/j.applthermaleng.2014.08.011.

[42] Wen CY, Chaung TZ. Entrainment Coal Gasification Modeling. Ind Eng Chem Process Des Dev 1979;18:684-95. doi:10.1021/i260072a020.

[43] Kabelac S, Vortmeyer D. VDI Heat Atlas Part K - Radiation. In: VDI, editor. VDI Heat Atlas. Second, Springer-Verlag Berlin Heidelberg; 2010.

[44] Nellis G, Klein S. Heat transfer. Cambridge University Press; 2008.

[45] Plou J, Martínez I, Grasa GS, Murillo R. Experimental carbonation of $\mathrm{CaO}$ in an entrained flow reactor. React Chem Eng 2019:899-908. doi:10.1039/c9re00015a. 


\section{List of figures}

Figure 1: Conceptual design of the power production using a carbonator in a solar power plant (cf stands for cooling fluid).

Figure 2: Conceptual design of the modelled carbonator (cf stands for cooling fluid).

Figure 3: Conceptual design of the energy storage process using a calciner in a solar power plant.

Figure 4: Case studies for the three proposed carbonator configurations.

Figure 5: CO2 capture efficiency achieved in the entrained flow reactor of Plou et al. [45] and in the simulations of this study under the same setup, as a function of the solid/gas mass ratio.

Figure 6: Variation of the residence time of the solids vs. the diameter of the particles.

Figure 7: Heat removal profile (left) and total removed thermal power for isothermal operation (right) vs. reactor's length and internal radius dimensions.

Figure 8: Final conversion vs. reactor's total length and internal radius dimensions (Configuration 1).

Figure 9: Temperatures and conversion profiles vs. axial position $(\mathrm{L}=52 \mathrm{~m}, \mathrm{r}=3.5 \mathrm{~m}$, Configuration 1).

Figure 10: Total exothermal power from carbonation (left) and total removed thermal power by cooling fluid (right) vs. reactor's total length and internal radius dimensions (Configuration 1).

Figure 11: Available thermal power from CO2 (left) and solids (right) vs. reactor's total length and internal radius dimensions (Configuration 1).

Figure 12: Final conversion vs. reactor's total length and internal radius dimensions (Configuration 2). 
Figure 13: Total exothermal power from carbonation (left) and total removed thermal power by cooling fluid (right) vs reactor's total length and internal radius dimensions (Configuration 2).

Figure 14: Temperatures and conversion profiles vs. axial position $(L=30 \mathrm{~m}, \mathrm{r}=3.5 \mathrm{~m}$, Configuration 2)

Figure 15: Available thermal power from $\mathrm{CO}_{2}$ (left) and solids (right) vs. reactor's total length and internal radius dimensions (Configuration 2).

Figure 16: Temperatures and conversion profiles (first stage: up, second stage: down) vs. axial position ( $r=1.5 \mathrm{~m}$, Configuration 3 )

\section{List of tables}

Table 1: Length required, removed thermal power by cooling fluid and available thermal power in the products in Configuration 1 and 2 (carbonators sized for $12 \%$ conversion).

Table 2: Sizes of carbonators, final conversion and thermal heats for Configuration 3. 